Portland State University

PDXScholar

$12-8-2020$

\title{
Human Energy in the Workplace: an Investigation of Daily Energy Management Strategies, Job Stressors and Employee Outcomes
}

Morgan Rose Taylor

Portland State University

Follow this and additional works at: https://pdxscholar.library.pdx.edu/open_access_etds

Part of the Psychology Commons

Let us know how access to this document benefits you.

\section{Recommended Citation}

Taylor, Morgan Rose, "Human Energy in the Workplace: an Investigation of Daily Energy Management Strategies, Job Stressors and Employee Outcomes" (2020). Dissertations and Theses. Paper 5625. https://doi.org/10.15760/etd.7497

This Thesis is brought to you for free and open access. It has been accepted for inclusion in Dissertations and Theses by an authorized administrator of PDXScholar. Please contact us if we can make this document more accessible: pdxscholar@pdx.edu. 
Human Energy in the Workplace: An Investigation of Daily Energy Management Strategies, Job Stressors and Employee Outcomes

by

Morgan Rose Taylor

A thesis submitted in partial fulfillment of the requirements for the degree of

\author{
Master of Science \\ in \\ Psychology
}

Thesis Committee:

Charlotte Fritz, Chair

Liu-Qin Yang

Todd Bodner

Portland State University

2020 
(C) 2020 Morgan Rose Taylor 


\begin{abstract}
Recent research has pointed to the benefits associated with the use of work-related energy management strategies for employee outcomes. Using the Conservation of Resources Theory and the Challenge and Hindrance Stressor Framework, the current study extends the energy management literature by examining day-level relationships between work-related energy management strategies (e.g., organizing, meaning-making, and prosocial strategies) and employee outcomes, namely, goal progress, work engagement, and relational energy respectively. Further, challenge and hindrance stressors are tested as day-level moderators of these relationships. Using experience sampling methods across 10 workdays, results showed that day-level organizing strategy use was related to higher goal progress whereas day-level prosocial strategy use was related to higher relational energy. Our findings also revealed four significant interaction effects, but only one was in line with our study hypotheses. Specifically, we found that challenge stressors moderated the positive relationship between day-level meaningmaking strategy use and dedication, a facet of work engagement, such that this relationship was stronger under higher levels of challenge stressors. These findings provide support that certain work-related energy management strategies are associated with unique benefits for employees and suggest that it may be advantageous to use specific strategies under certain conditions.
\end{abstract}


Table of Contents

Abstract.....................................................................

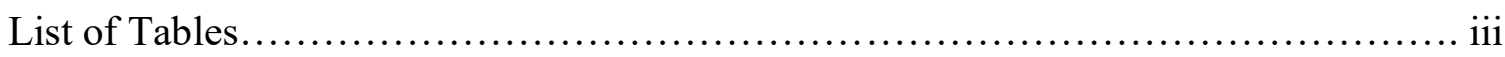

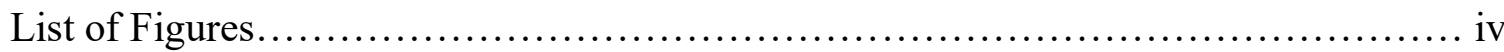

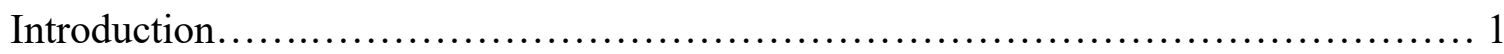

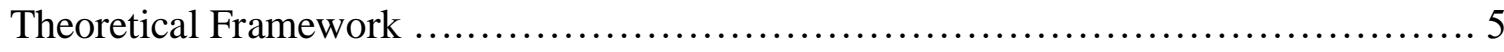

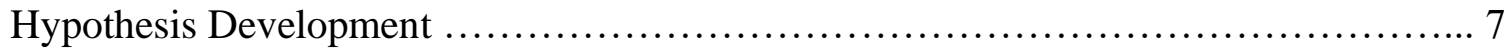

Method.................................................................. 23

Participants and Procedure......................................... 23

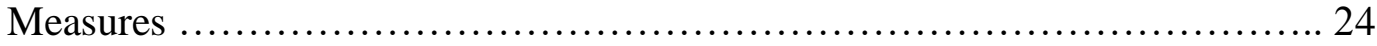

Analytic Approach ................................................. 26

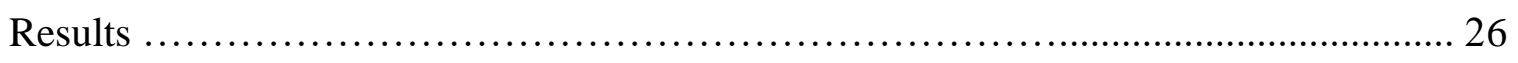

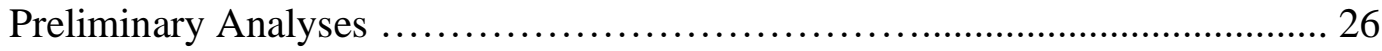

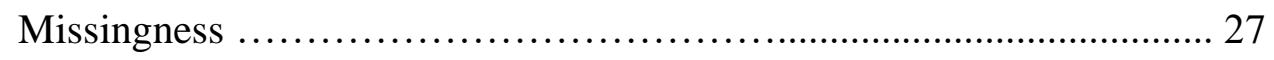

Multi-Level Confirmatory Factor Analyses ......................... 27

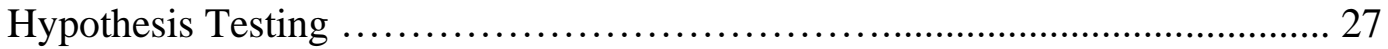

Sensitivity Analyses .............................................................. 31

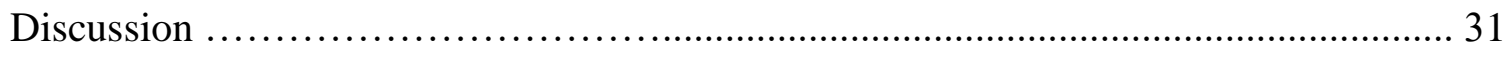

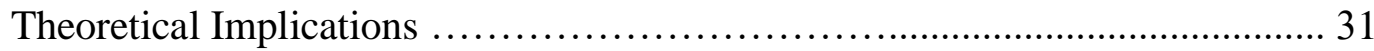

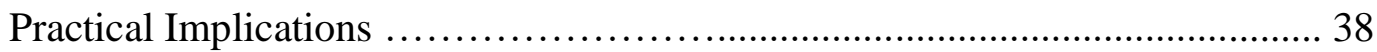

Limitations and Future Directions ................................................... 39

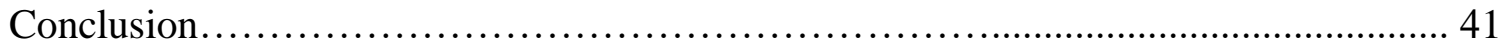

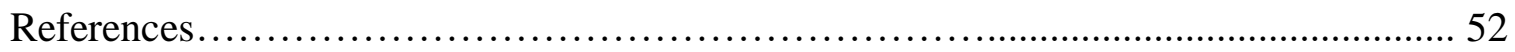

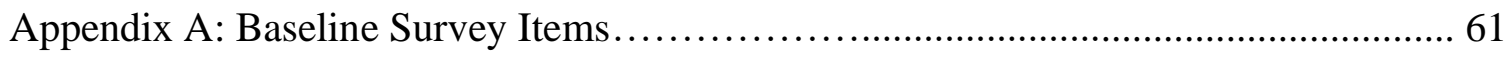

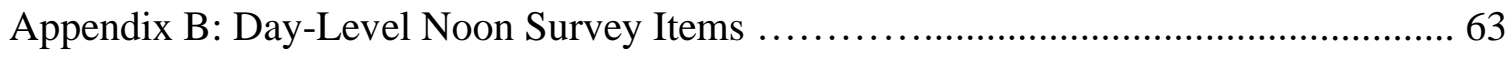

Appendix C: Day-Level Post-Work Survey Items .............................................. 65 


\section{List of Tables}

Table 1: Means, Standard Deviations, and Correlations Among Study Variables...... 42

Table 2: Multi-Level Factor Analysis Results .......................................... 43

Table 3. Moderating effect of challenge stressors and organizing strategies on goal

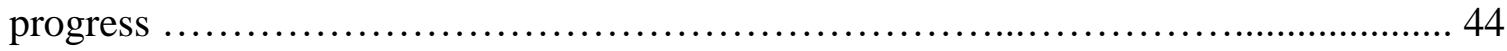

Table 4. Moderating effect of hindrance stressors and organizing strategies on goal

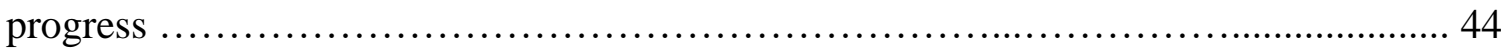

Table 5. Moderating effect of challenge stressors and meaning-making strategies on

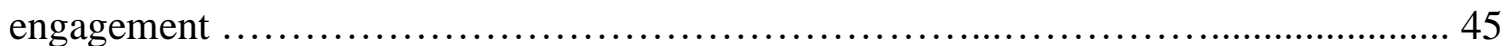

Table 6. Moderating effect of hindrance stressors and meaning-making strategies on

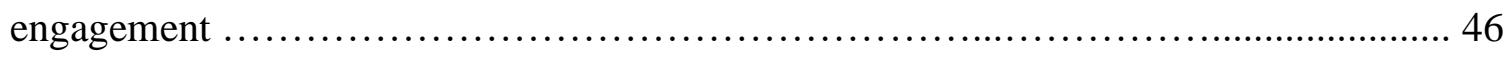

Table 7. Moderating effect of challenge stressors and prosocial strategies on relational energy

Table 8. Moderating effect of challenge stressors and prosocial strategies on relational energy 
Table of Figures

Figure 1: Graphic representation of the interaction between organizing strategies and

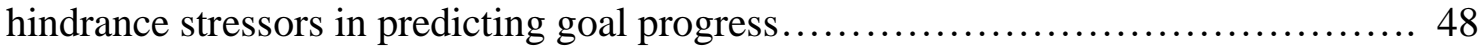

Figure 2: Graphic representation of the interaction between meaning-making strategies and challenge stressors in predicting dedication................................ 49

Figure 3: Graphic representation of the interaction between meaning-making strategies

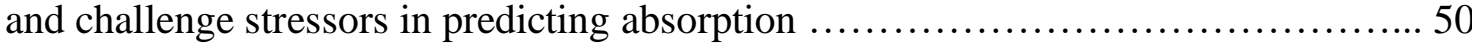

Figure 4: Graphic representation of the interaction between meaning-making strategies and hindrance stressors in predicting dedication................................ 51 


\section{Introduction}

"As employees and organizations continually strive to do more with less, human energy in the workplace is an increasingly critical and relevant issue in organizational research" (Owens, Baker, Sumpter, Cameron, 2016, p. 35).

Over the past decade in organizational research, there has been growing interest in how employees maintain, sustain, and restore their energy throughout the workday. According to a recent Gallup study of 7,500 full-time employees, " $23 \%$ of employees reported feeling burned out at work very often or always, while an additional $44 \%$ reported feeling burned out sometimes" (Weigert \& Agrawal, 2018). This raises the following questions: what strategies can employees use to sustain higher levels of energy throughout the workday, are these strategies linked to specific outcomes on the job, and under what conditions are these strategies most effective?

Recent research has pointed to the benefits of energy management strategies at work and their association with positive outcomes for employees (e.g., Fritz, Lam, \& Spreitzer, 2011; Parker, Zacher, de Bloom, Verton, \& Lentink, 2017; Zacher, Brailsford, \& Parker, 2014). Energy management strategies at work refer to activities that individuals deliberately use throughout the workday to sustain their energy levels (Parker et al., 2017). One group of energy management strategies, work-related strategies, occur during the course of work and foster intrinsic motivation through satisfying basic psychological needs (Fritz et al., 2011; Parker et al., 2017). These strategies include workplace behaviors such as helping a coworker and reflecting on the meaning of one's work (Fritz et al., 2011). 
This study will focus on work-related strategies as a form of energy management at work and will contribute to the energy management literature in the following ways. First, work-related strategies are a largely understudied form of energy management. Initial evidence suggests that these strategies may be more helpful in sustaining one's energy compared to the use of other energy management strategies (Fritz et al., 2011). However, past research investigating work-related strategies have often relied on less rigorous research designs such as cross-sectional studies, thereby limiting our understanding of which strategies are most effective for momentary energy gains. Thus, by examining work related energy management strategies using experience sampling methods, this study will provide a deeper understanding of how the day-to-day fluctuations in individual's energy levels are related to specific energy management strategies used that day.

Second, of the limited empirical studies examining work-related energy management strategies, Parker et al.'s study (2017) is the only study to examine these strategies at the day-level. Their study examined the day-level relationships between three work-related strategies - organizing, meaning-making, and prosocial strategies and day-level emotional exhaustion and job satisfaction. Further, they also examined whether these relationships were moderated by job stressors. While this study served as an initial examination of the day-level associations between work-related energy management strategies and employee well-being outcomes, it had some limitations that this study aims to address. First, the study broadly examined whether day-level job satisfaction and emotional exhaustion were related to each work-related energy management strategy (e.g., organizing, meaning-making, prosocial). Therefore, the 
design did not allow for the examination of the unique relationship between each strategy and specific employee outcomes. In other words, the use of certain work-related energy management strategies may be associated with unique benefits for employees and thus it may not be advantageous to assume all strategies are equally associated with the same employee outcomes as these outcomes may vary based on the strategy used. The present study aims to build upon Parker and colleague's (2017) work by investigating whether each work-related strategy is associated with unique benefits for the individual by examining perceived goal progress, work engagement, and relational energy as outcomes linked to higher energy in the workplace that day.

Furthermore, it is important to understand how different types of work stressors may interact with energy management strategies to affect employees' experiences throughout the workday. Parker and colleagues (2017) examined the moderating role of work stressors using Spector and Jex’s Quantitative Workload Inventory (QWI; 1998). They measured work stressors in the baseline survey arguing that chronic work stressors are "experienced as a more intense and salient threat of resource loss, and as such would be when we observe the benefit of energy management" (p. 10). However, it is likely that day-level fluctuations in certain types of work stressors may be associated with the frequency and use of specific work-related strategies that day. For example, challenge stressors are stressors associated with achievement and other potential gains whereas hindrance stressors are stressors that impede achievement and hinder development (Cavanaugh, Boswell, Roehling, \& Boudreau, 2000). Past day-level studies have found that day-to-day fluctuations in challenge and hindrance stressors have differential relationships with various outcomes such as work engagement, affect (Tadic, Bakker, \& 
Oerlemans, 2015), attentiveness, anger, and anxiety (Rodell and Judge, 2009). Further, the examination of day-to-day fluctuations in challenge and hindrance stressors may provide insight to potential boundary conditions of these strategies, thus shedding light on which work-related strategies are most strongly related to employee outcomes and under which conditions (i.e., higher versus lower challenge and hindrance stressors).

\section{Effectiveness of Work-Related Energy Management Strategies}

In 2011, Fritz and colleagues published a seminal study that laid the groundwork for future research in the energy management domain. They examined relationships between two forms of energy management strategies (i.e., micro-breaks and work-related strategies) and two dimensions of human energy, namely, experienced vitality and fatigue. They found that work-related strategies were related to higher levels of vitality and unrelated to fatigue whereas the use of microbreaks (i.e., short breaks unrelated to work) were related to lower vitality and higher fatigue. These findings provided preliminary evidence that work-related energy management strategies may be the most helpful in maintaining one's energy throughout the workday (Fritz et al. 2011). Building on these findings as well as on more recent findings regarding energy management strategies, this study will focus on day-level relationships between work-related energy management strategies and three daily employee outcomes.

While Fritz and colleagues (2011) work was based on a cross-sectional study design, research in the energy management domain has continued to build upon this study by exploring the unique benefits of work-related strategies. Building upon Fritz and colleague's (2011) cross-sectional study, Zacher et al. (2014) conducted a day-level study on work-related strategies and found that these strategies were unrelated to both vitality 
and fatigue at the within-person level (Zacher et al., 2014). de Bloom, Kinnunen, and Korpela (2015) conducted a cross-sectional study and found that certain work-related energy management strategies, specifically, focusing on what gives someone joy at work, setting new goals, and offering to help others, were most strongly correlated with selfreported health (e.g., "How would you rate your general health status?”), work engagement, and job performance. Overall, past findings regarding work-related strategies are mixed, thus warranting further research to elucidate the relationship between specific work-related energy management strategies and employee outcomes.

\section{Theoretical Framework}

The Conservation of Resources Theory (COR; Hobfoll, 1989) posits that individuals "strive to obtain, retain, foster, and protect those things they centrally value" (Hobfoll, Halbesleben, Neveu, \& Westman, 2018, p. 104). Resources refer to objects, conditions, characteristics, or energies that are highly valued and re-invested to further the attainment of additional resources (Hobfoll, 1989; Hobfoll et al., 2018). COR Theory is guided by a set of key principles and corollaries. The Primacy of Loss Principle states that resource loss is more salient than resource gain. Further, this principle suggests that resource loss negatively affects individuals at faster rates compared to resource gain. Applying this principle in the context of energy management, resource loss may lead to energy depletion at a faster rate than resource gain which may be associated with slower increases in energy. Furthermore, feelings of energy or feeling energized may be temporary or fleeting. Therefore, the use of experience sampling methods will allow us to examine work-related energy management strategy use and potential short-term resource gains that day. The Resource Investment Principle asserts that in order to protect against 
or recover from resource loss, one must invest resources. Therefore, the use of workrelated strategies throughout the workday may serve as an investment in resources to protect against further resource loss (i.e., decreases in energy) and ensure future resource gain (i.e., increases in energy). The Gain Paradox Principle states that resource gain becomes increasingly valuable when resource loss is highly salient. Therefore, the use of work-related strategies may become increasingly important when employees face higher job demands during the workday. Finally, according to the Resource Loss Cycle Corollary, higher levels of job stressors are associated with greater resource loss and these losses make it difficult to combat future resource loss resulting in loss spirals. As a result, higher levels of job stressors may reduce the positive outcomes associated with the use of energy management strategies, therefore, calling into question the importance of specific types of work-related strategies used when employees experience certain stressors at work.

Past research also supports the usefulness of a two-dimensional framework of work stressors (LePine, Podsakoff, \& LePine, 2005). One dimension, challenge stressors, are viewed as obstacles that can promote and foster learning, growth, and achievement (Crawford, LePine, \& Rich, 2010; LePine et al., 2005). Examples of challenge stressors include time pressure, job scope, high workload and responsibility. LePine and colleagues (2005) argued that challenge stressors are associated with increased motivation due to the perceived relationship between increased effort and the attainment of valued outcomes. For example, employees with higher job responsibility may feel that they can meet the demands associated with this stressor through increased effort which can lead to valued outcomes such as a promotion (Crawford et al., 2010). Past meta- 
analytic findings support this perspective indicating that challenge stressors are indirectly and positively related to job performance through motivation (LePine et al., 2005).

The second dimension, hindrance stressors, are stressors that act as a constraint or barrier to individual growth and achievement (Cavanaugh et al., 2000; LePine et al., 2005). Examples of hindrance stressors include daily hassles, organizational politics, role ambiguity, and red tape (LePine et al., 2005). In contrast to challenge stressors, LePine and colleagues (2005) argued that hindrance stressors are associated with lower motivation because individuals do not perceive that increased effort and persistence will lead to valued outcomes (LePine et al., 2005). For example, individuals who experience role overload may believe that regardless of the amount of time or effort expended, one will not be able to complete all the necessary tasks in the designated time. Therefore, increased effort will not lead to valued outcomes and should be associated with lower job performance. Meta-analytic evidence also supports this perspective indicating that hindrance stressors are negatively and indirectly related to performance through motivation (LePine et al., 2005).

\section{Hypothesis Development}

Past research has examined three types of work-related energy management strategies, namely, organizing, meaning-making, and prosocial strategies (Parker et al., 2017). Organizing strategies refer to "future oriented behaviors" that support the completion of one' work tasks (Parker et al., 2017, p. 3). Common organizing strategies include checking and updating your schedule, making a to-do list, and setting a new goal (Parker et al., 2017). Organizing strategy use should be positively related to goal progress. Day-level goal progress refers to the perception of progress and/or achievement 
of one's work related goals that day (Low, Overall, Hammond \& Girme, 2017). There is some cross-sectional evidence indicating that organizing strategies are related to performance outcomes. For instance, de Bloom et al. (2015) found that making a to-do list was positively related to contextual job performance and creativity on the job and that setting a new goal was positively related to both task and contextual performance and creativity at work. Several lines of thinking and evidence suggest that goal progress and accomplishment is energizing for individuals because they "expect many psychological and practical outcomes from setting and attaining one's goals" (Locke \& Latham, 2002). Therefore, setting and accomplishing goals through the use of organizing strategies may be energizing for individuals.

According to COR Theory's Investment Principle, people must invest resources to ensure future resource gain (Hobfoll et al., 2018). Applying this principle to the energy management domain, one way to invest and gain resources is through the use of energy management strategies which are argued to have positive short-term effects (Parker et al., 2017). Organizing strategies should protect against resource loss in the form of energy resources by inhibiting further resource depletion (i.e., COR Investment Principle) and should also be associated with resource gains evident through increases in personal resources such as self-efficacy or motivation (Hobfoll et al., 2018). It has also been suggested that the use of organizing strategies increases concentration and expands one's capacity to invest effort into completing work. As a result, personal resources associated with organizing strategy use should help manage one's time and direct their attention towards achieving work goals becoming visible through higher levels of goal progress that day (Hobfoll et al., 2018; Parker et al., 2017; Trougakos \& Hideg, 2009). Therefore, 
I hypothesize that day-level organizing strategy use should help individuals better direct their effort to achieve higher levels of goal progress that day through the mobilization of personal energy resources.

Hypothesis 1: Day-level organizing strategies will be positively related to daylevel goal progress.

Meaningful work refers to the belief that one's work is purposeful and significant (Pratt \& Ashford, 2003). Employees can utilize meaning-making strategies, which refer to "behaviors that help employees see the broader meaning of their work" (Parker et al., 2017, p. 3). According to COR Theory, purpose and meaning in life are commonly valued resources (Hobfoll et al., 2018). Kahn (1990) argued that individuals experience meaningfulness when they feel "worthwhile, useful, and valuable - as though they made a difference" (p. 704). Further, Khan argued that psychological meaningfulness is linked to engagement such that situations characterized by psychological meaningfulness are associated with higher levels of engagement (Khan, 1990). Kahn (1990) defined psychological meaningfulness as "a feeling that one is receiving a return on investments of one's self in a currency of physical, cognitive, or emotional energy" (p. 704). This suggests that individuals who perceive higher levels of meaningfulness in their work should also exhibit higher levels of work engagement. Therefore, individuals who perceive their work as more meaningful are more likely to be invested in their work (May, Gilson, \& Harter, 2004). Empirical findings support this perspective. May and colleagues (2004) examined the relationship between three psychological conditions (e.g., psychological safety, meaningfulness, and availability) and work engagement. They referred to psychological meaningfulness as a "psychological state or condition at work" 
defined as "the value of a work goal or purpose, judged in relation to an individual's own ideas or standards" (May et al., 2004, p. 14). They found that psychological meaningfulness was most strongly correlated with work engagement among the three psychological conditions (e.g., psychological safety, meaningfulness, and availability).

Recent research on meaning-making energy management strategies has indicated that these strategies are related to a host of well-being, attitudinal, and performance outcomes. For instance, Fritz and colleagues (2011) found that the use of three meaningmaking strategies - focusing on what gives one joy at work, reflecting how one makes a difference, and reflecting on the meaning of work - were positively related to subjective vitality. Zacher and colleagues (2014) found that the following strategies - reflecting on the meaning of my work and reflecting on how I make a difference at work - were also associated with subjective vitality. de Bloom and colleagues (2015) found that the following meaning-making strategy - I focus on what gives me joy at work - was one of three strategies most strongly and consistently related to self-reported health, work engagement, creativity, as well as task and contextual performance at work.

While the relationship between meaning-making strategies and work engagement have been previously explored using cross-sectional methods (de Bloom et al., 2015), the question remains whether this relationship exists at the day-level. In addition, only one meaning-making strategy was examined in de Bloom and colleague's study - focusing on what gives me joy at work - in relation to two of the three facets of work engagement, namely vigor and dedication. Therefore, I propose that day-level meaning-making strategy use will be positively associated with all three facets of work engagement (e.g., vigor, dedication, and absorption). Daily work engagement refers to a "positive, 
fulfilling, work-related state of mind that is characterized by vigor, dedication, and absorption" (Schaufeli, Salanova, González-Romá, \& Bakker, 2002, p. 74) and "reflects a transient state of mind that exists on a given movement and fluctuates within the same individual over short periods of time" (Bakker, 2014, p. 229; Sonnentag, Dormann, \& Demerouti, 2010). Dedication refers to one's commitment and experience of significance of one's work whereas vigor refers to the experience of higher levels of energy while working (Schaufeli \& Bakker, 2010). Meaning-making strategies should be related to dedication and vigor, as these strategies serve as a salient reminder of the value of one's work (e.g., dedication) while also prompting one to feel energized and positively engaged in one's work that day (e.g., vigor) (Parker et al., 2017). Absorption refers to being fully immersed in one's work (Schaufeli \& Bakker, 2010). Some research suggests that "experienced meaningfulness of work is a critical psychological state necessary to the development of internal work motivation" and as such may manifest itself through increased feelings of absorption at work (Rosso, Dekas, \& Wrzesniewski, 2010, p. 96). Therefore, meaning-making energy management strategy use may also be uniquely related to each facet of work engagement (e.g., vigor, dedication, absorption).

Hypothesis 2: Day-level meaning-making strategies will be positively related to day-level work engagement.

Prosocial energy management strategies refer to altruistic behaviors in the workplace that promote positive interactions with others (Parker et al., 2017). Some research has suggested that prosocial behaviors in the workplace are energizing. One stream of research has focused on the energizing benefits associated with prosocial behaviors. Lanaj, Johnson, and Wang (2016) examined the relationship between 
prosocial impact and feelings of energy. They found that perceived prosocial impact was negatively related to energy depletion while controlling for prior resource depletion. These findings suggest that perceived social impact may actually have energy-enhancing properties, as opposed to energy-depleting properties (Lanaj et al., 2016). Furthermore, a qualitative study by Shraga and Shirom (2009) examined the antecedents of vigor at work and found that meaningful interpersonal relationships such as appreciation from others, support from coworkers, cooperation with others, and warm relations were most frequently related to experiencing vigor at work.

There has also been growing empirical research specifically examining the benefits associated with prosocial energy management strategies. Previous studies have shown that certain prosocial strategies are related to subjective vitality at both the between and within person level. Fritz and colleagues (2011) found that prosocial strategies - doing something that made a colleague happy and making time to show gratitude to someone at work - were related to subjective vitality at the between person level. In line with Fritz and colleague's findings, Zacher and colleague's (2014) day-level study found that offering to help someone at work, doing something that made a colleague happy, and making time to show gratitude for someone at work was positively related to subjective vitality. De Bloom and colleagues (2015) found that offering to help someone at work was one of three work related strategies most strongly and consistently related to self-reported health, work engagement, task as well as contextual performance, and creativity at work. Finally, Parker and colleagues found that day-level prosocial strategies- doing something that made a colleague happy, making time to show gratitude 
for someone at work, and offering to help someone at work - were positively related to day-level job satisfaction.

In line with the Conservation of Resources Theory (Hoboll et al., 2018), energy is considered a limited resource that individuals can replenish through social interactions with others (Owens et al, 2016). Recent research has started to examine relational energy at work, or the "heightened level of psychological resourcefulness generated from interpersonal interactions that enhances one's capacity to do work" (Owens et al., 2016, p. 37). In other words, relational energy is a form of emotional energy that can be fostered through social interactions with others (Baker, 2019; Owens et al., 2016). This form of energy has been found to positively relate to work engagement and job performance (Owens et al., 2016). Further, Owens and colleagues (2016) found that the relationship between relational energy and job performance was mediated by work engagement across three time points (Owens et al., 2016). Research on relational energy also has unique implications on group level dynamics, specifically group emotion and productive energy (Baker, 2019). Therefore, I hypothesize that on days on which employees report utilizing more prosocial energy management strategies (i.e., strategies that promote positive interactions with others), they will also experience higher levels of positive and energy enhancing interactions with others visible through greater relational energy that day.

Hypothesis 3: Day-level prosocial strategies will be positively related to day-level relational energy.

\section{The Moderating Role of Challenge and Hindrance Stressors}


Research on job stressors by Cavanaugh and colleagues (2000) found that two related yet empirically different types of stressors, namely challenge and hindrance stressors, were differentially related to attitudinal and behavioral work outcomes. Emerging research on energy management has exclusively focused on general work stressors (e.g., Kim et al., 2017; Parker et al., 2017) thereby limiting our understanding of how different stressors experienced throughout the workday may uniquely and differentially play a role in the relationships between work-related energy management strategies and employee outcomes. Moreover, I hypothesize that the relationship between specific work-related energy management strategies and employee outcomes may be strengthened or weakened based on the type and frequency of these two types of stressors within the workday. Research has supported the idea that challenge and hindrance stressors fluctuate throughout the workday and from day to day (Rodell and Judge, 2009). Thus, examining daily fluctuations in a broader range of these stressors allows for a deeper investigation of whether the relationships between these strategies and employee outcomes are stable or fluctuate across days on which the frequency of stressor type may vary.

Building upon and expanding the investigation of the relationship between different types of stressors and work-related energy management strategies, I propose that daily challenge stressors should moderate the relationship between day-level organizing strategy use and goal progress. Research examining boundary conditions associated with energy management strategies remains limited. Parker and colleagues (2017) examined workload, as one chronic challenge stressor and boundary condition in their study. Using experience sampling methods, they found that workload moderated the relationship 
between day-level organizing strategies and job satisfaction such that organizing strategy use was positively related to job satisfaction for employees with lower workload whereas this relationship was negative for employees with higher workload (Parker et al., 2017). They also found that workload moderated the relationship between day-level organizing strategy use and emotional exhaustion such that this relationship was negative for employees with lower workload and positive for employees with higher workload.

Challenge stressors, while requiring effort, are unique in that these stressors promote learning, growth, and achievement (LePine et al., 2005, Crawford et al., 2010). These stressors are associated with higher motivation due to the perceived relationship between increased effort and the attainment of valued outcomes. As a result, individuals use problem-focused coping when faced with challenge stressors (LePine et al., 2005). Rather than distracting oneself from the stressor (e.g., emotion focused coping), problem focused coping aims to directly alter the stressful situation (Folkman \& Lazarus, 1990). In line with this perspective, I hypothesize that on days on which employees experience a higher frequency of challenge stressors, the positive relationship between day-level organizing strategy use and goal progress should be stronger than on days with lower daily challenge stressors. Specifically, when experiencing challenge stressors, individuals will use problem focused coping thereby continuing to work on their goals despite encountering these stressors. Further, individuals will continue to work towards their goals because they perceive that the investment in organizing strategies will help direct their attention and will increase one's effort accordingly, thereby leading to valued outcomes such as goal progress or achievement. Therefore, on days with higher challenge 
stressors, the value of organizing strategies will increase, and individuals will be more likely to invest in these strategies related to higher goal progress.

Hypothesis 4a: Day-level challenge stressors will moderate the relationship between day-level organizing strategies and day-level goal progress. The positive relationship between day-level organizing strategies and day-level goal progress will be stronger on days on which employees experience higher challenge stressors than on days with lower challenge stressors.

Whereas challenge stressors should strengthen the relationship between organizing strategy use and goal progress, hindrance stressors should weaken this relationship because these stressors act as constraints that impede goal accomplishment (Cavanaugh et al., 2000). Unlike challenge stressors, hindrance stressors are associated with lower motivation because valued outcomes are not perceived as attainable through increased effort and persistence (LePine et al., 2005). Therefore, on days with higher hindrance stressors, these stressors act as barriers that limit goal progress regardless of the organizing strategies implemented. Interestingly, some research findings suggest that the use of certain energy management strategies may be most beneficial for employees working under lower job demands (Parker et al, 2017). For instance, Parker and colleagues (2017) found that lower work stressors moderated the relationship between the day-level organizing strategy use and job satisfaction and emotional exhaustion. The researchers argued that using certain organizing strategies (e.g., creating to-do lists) may actually increase perceived demands such as the workload required to accomplish one's goal. It might be expected that a growing to-do list may become overwhelming, especially under conditions associated with higher hindrance stressors (Parker et al., 
2017). Therefore, on days with higher hindrance stressors, the relationship between daylevel organizing strategy use and goal progress will become weaker because hindrance stressors will continue to impede goal progress despite the strategy used.

Hypothesis 4b: Day-level hindrance stressors will moderate the relationship between day-level organizing strategies and day-level goal progress. The positive relationship between day-level organizing strategies and day-level goal progress will be weaker on days on which employees experience higher hindrance stressors than on days with lower hindrance stressors.

Challenge stressors should moderate the relationship between day-level meaningmaking strategies and work engagement. Meaning is characterized by having a sense of purpose, goals, challenge, achievement, and growth in life (Fairlie, 2011). These are arguably some of the most commonly valued resources according to COR Theory (Hobfoll et al., 2018). Individuals are inherently motivated to attain meaning in their lives, including through one's work, which can be a primary source of meaning (Steger \& Dik, 2010). It has been commonly argued that employees who find meaning, value, and significance in their work will often be more engaged (Fairlie, 2011; Geldenhuys, Laba, \& Venter, 2014; May et al., 2004). Indeed, research has supported this perspective, indicating that meaningful work is associated with engagement in one's job (Farilie, 2011; Geldenhuys et al., 2014; May et al, 2014; Kahn, 1990). A cross-sectional study by Geldenhuys and colleagues (2014) examined psychological meaningfulness as an antecedent of engagement. In support of their study hypothesis, they found that psychological meaningfulness did predict work engagement (Geldenhuys et al., 2014). Similarly, Farlie (2011) examined meaningful work characteristics as antecedents of 
engagement. Meaningful work characteristics refer to specific job characteristics that foster satisfaction and meaning of one's work (e.g., intrinsic rewards). Farlie (2011) found that not only were meaningful work characteristics antecedents of work engagement, meaningful work characteristics demonstrated the strongest relationship with engagement ( $r=.77$ ) compared to other study outcomes. Most notably, they found that meaningful work characteristics accounted for $16 \%$ of the total variance in engagement while controlling for other job characteristics. However, relationships are complex, and limited research has examined boundary conditions associated with this relationship, especially in the context of energy management. For instance, Parker and colleagues (2017) found that work stressors moderated the relationship between day-level meaning-making energy management strategies and emotional exhaustion. Specifically, this relationship was stronger for individuals who reported lower versus higher levels of chronic work stressors (Parker et al., 2017).

With the goal of expanding our understanding of the boundary conditions associated with meaning-making strategies and engagement at the day level, I hypothesize that challenge stressors should strengthen the relationship between day-level meaning-making strategies and the three facets of engagement (e.g., vigor, dedication, absorption). For instance, challenge stressors foster opportunities associated with growth and achievement, core facets of meaning, and as a result should strengthen the relationship between the perceived value and significance of one's work and dedication that day (Crawford, LePine, \& Rich, 2010). Challenge stressors also have the potential to be energizing due to the achievement and growth-oriented nature of these stressors. This should enhance the perceived value of one's work associated with higher levels of 
energized work states (e.g., vigor). Finally, challenge stressors are associated with the belief that valued outcomes can be attained through increased effort. Therefore, challenge stressors should strengthen the relationship between meaning-making strategies and absorption due to the stronger state of internal motivation and the perceived relationship between effort required to attain one's goals and the actual attainment of the goal (e.g., absorption). Therefore, I hypothesize that day-level challenge stressors may serve as an important and previously unexplored boundary condition associated with the relationship between day-level meaning making strategies and work engagement.

Hypothesis 5a: Day-level challenge stressors will moderate the relationship between day-level meaning-making strategies and day-level work engagement. The positive relationship between day-level meaning-making strategies and daylevel work engagement will be stronger on days on which employees experience higher challenge stressors than on days with lower challenge stressors.

On the other hand, hindrance stressors should weaken the relationship between day-level meaning-making strategies and all three facets of engagement (e.g., dedication, vigor, absorption). Hindrance stressors unnecessarily thwart growth and development and should weaken the relationship between the perceived value and significance of one's work and dedication that day (Crawford, LePine, \& Rich, 2010). Hindrance stressors are also de-energizing due to the burdensome and difficult nature of these stressors. These stressors should be related to a decrease in the perceived value of one's work and vigor at work. Finally, unlike challenge stressors, hindrance stressors hinder the perception that increased effort is associated with the attainment of valued outcomes. Therefore, hindrance stressors should weaken the relationship between meaning-making strategies 
and absorption due to the decreased state of internal motivation and the perceived negative relationship between one's effort and the attainment of goals associated with higher levels of absorption. Therefore, day-level hindrance stressors should be an important and previously unexplored boundary condition of the relationship between daylevel meaning making strategies and work engagement.

Hypothesis 5b: Day-level hindrance stressors will moderate the relationship between day-level meaning-making strategies and day-level work engagement. The positive relationship between day-level meaning-making strategies and daylevel work engagement will be weaker on days on which employees experience higher hindrance stressors than on days with lower hindrance stressors. Challenge stressors should also moderate the relationship between day-level prosocial strategies and relational energy. Past research has found that work stressors moderated the relationship between day-level prosocial strategy use and emotional exhaustion. Interestingly, the relationship between the prosocial strategy use and emotional exhaustion was weaker for employees with higher job demands (Parker et al., 2017). Using experience sampling methodology, Weinstein and Ryan (2010) examined the relationship between helping (e.g., prosocial behaviors) and vitality that day. Prosocial behaviors were defined as activities that helped someone else or were related to a good cause (Weinstein \& Ryan, 2010). Consistent with their hypotheses, results indicated that on days on which employees reported engaging in helping behaviors, they also reported higher levels of vitality that day. Furthermore, on days when employees reported helping behaviors due to autonomous motives (e.g., helping on behalf of their own will), this was also associated with higher levels of vitality that day. These findings 
suggest there are energizing benefits associated with helping behaviors, especially if they are performed on behalf of the helper's own will as opposed to helping as an expectation of the job. Further, prosocial behaviors at work can be linked to benefits for both the giver and the recipient of help (Weinstein \& Ryan, 2010). Helpers may develop close relationships with the recipient of help as "helping is inherently interpersonal and thus impacts relatedness by directly promoting closeness to others, positive responses from others, and cohesiveness or intimacy" (Weinstein \& Ryan, 2010, p. 224). Taken together, these findings provide support that individuals may experience higher levels of relational energy after providing help to others at work.

Building upon this initial hypothesis, I hypothesize that challenge stressors should moderate the relationship between the day-level prosocial strategy use and relational energy. In line with the Resource Investment Principle, people must invest in resources in order to reduce resource loss and increase resource gain (Hobfoll et al., 2018). Prosocial strategy use represents a form of resource investment that can mitigate resource loss and increase resource gain visible through higher relational energy that day. Under conditions characterized by higher challenge stressors, individuals should recognize the benefits associated with engaging in prosocial behaviors with others, as these behaviors' present opportunities for personal growth and development and are positive workplace behaviors beyond one's prescribed job duties. More importantly, under these conditions, individuals may see helping others as a challenge that fosters resources through positive interactions with others. Therefore, investing oneself through engaging in prosocial behaviors such as helping a coworker may lead to energizing and resource enhancing interactions, thereby 
strengthening the relationship between prosocial strategy use and relational energy that day.

Hypothesis 6a: Day-level challenge stressors will moderate the relationship between day-level prosocial strategies and day-level relational energy. The positive relationship between day-level prosocial strategies and day-level relational energy will be stronger on days on which employees experience higher challenge stressors than on days with lower challenge stressors.

Lastly, hindrance stressors should also moderate the relationship between the daylevel prosocial strategy use and relational energy. Prosocial strategies should be perceived as an inadequate investment in resources as these behaviors are resource depleting under conditions characterized by higher hindrance stressors. Specifically, these stressors are associated with decreased motivation to help others as these stressors are positively related to exhaustion (LePine, LePine, \& Jackson, 2004) and withdrawal behaviors (Podsakoff, LePine and LePine, 2007). Higher hindrance stressors should further weaken the relationship between prosocial strategy use and relational energy because these stressors are de-energizing (e.g., reduced effort and persistence), impede personal growth that could be derived from these positive interactions with others, trigger negative emotions, and are related to disengagement thereby making it even less likely that individuals will engage in these prosocial behaviors. Therefore, under these conditions, prosocial strategy use is an inadequate strategy for resource investment as these behaviors are associated with resource depleting interactions.

Hypothesis 6b: Day-level hindrance stressors will moderate the relationship between day-level prosocial strategies and day-level relational energy. The 
positive relationship between day-level prosocial strategies and day-level relational energy will be weaker on days on which employees experience higher hindrance stressors than on days with lower hindrance stressors.

\section{Method}

\section{Participants and procedure}

Participants were recruited from a cybersecurity company in the Midwest. A total of 399 recruitment emails were sent with a link to a baseline survey. At the end of the baseline data collection period, 209 baseline responses were collected. Out of the 209 initial responses, a total of 66 survey responses were removed due to incomplete survey responses and an additional eight survey responses were removed due to duplicate responses resulting in a final sample of 135 participants (34\% participation response). On average, participants were 43.36 years old $(S D=13.19)$, had an organizational tenure of 6.10 years $(S D=7.53)$, and worked 44.27 hours per week $(S D=6.15)$. Most of the sample was male $(68 \%)$ and white $(93 \%)$. A total of $45 \%$ of the participants reported having a bachelor's degree. This sample also represented a range of job levels including front line workers $(47 \%)$, leads $(20 \%)$, managers $(12 \%)$, directors $(7 \%)$, supervisors $(6 \%)$, vice presidents (4\%), and executives (4\%).

Only participants who completed the baseline survey were invited to participate in the daily surveys. Participants were then asked to complete two short daily surveys for 10 consecutive workdays. The first daily survey was sent to participants at 11:00 a.m. and remained open until 2:00 p.m. Participants reported the use of work-related energy management strategies in addition to any challenge and hindrance stressors experienced that morning. The second survey was sent to participants at 2:30 p.m. and remained open 
until 8:30 p.m. Participants reported their goal progress, work engagement, and relational energy that afternoon. By matching the daily survey responses, we obtained 488 unique observation days and 725 total survey completions, yielding a response rate of $27 \%$ (725 out of 2700).

\section{Measures}

Challenge and Hindrance Stressors were assessed using eight items to assess daily challenge stressors and eight items to assess daily hindrance stressors from Rodell \& Judge's (2009) Daily Challenge and Hindrance Stressor Scale. Participants indicated the extent to which they agreed with each item using a five-point Likert scale ranging from (1) strongly disagree to (5) strongly agree. Sample items for challenge and hindrance stressors included "This morning at work, I experienced severe time pressures in my work" and "This morning at work, I had to go through a lot of red tape to get my job done" respectively. The average Cronbach's alpha across observations for .78 and .71 for challenge and hindrance stressors respectively.

Energy Management Strategies were assessed with a nine-item scale validated by Parker et al. (2017). These items were adapted for day level measurement based on past work by Fritz et al. (2011) and Zacher et al. (2014). Participants indicated the frequency in which they used three types of strategies (e.g., organizing, meaning-making, prosocial) to manage their energy at work using a scale ranging from (1) not at all (5) very much. Sample items for organizing, meaning-making, and prosocial strategies included "This morning at work, I managed my energy by making a to-do list", "This morning at work, I reflected on the meaning of my work", and "This morning at work, I offered help to someone at work" respectively. The average Cronbach's alpha across 
observations for organizing, meaning-making, and prosocial strategies was $.67, .70$, and .80 respectively.

Goal Progress was assessed using three items adapted from Low, Overall, Hammond, and Grimes' (2017) Goal Success Measure. Participants indicated the extent to which they agreed with a list of statements using a scale ranging from (1) strongly disagree to (5) strongly agree. Sample items included "This afternoon at work, I made great progress towards my goals" and "This afternoon at work, my attempts to achieve my goals have been successful". The average Cronbach's alpha across observations was .92.

Work Engagement was assessed using Schaufeli, Bakker, and Salanova’s (2006) State Work Engagement (UWES) scale adapted and validated for day-level measurement occasion (Breevaart, Bakker, Demerouti, \& Hetland, 2012). Participants indicated the extent to which they agreed with nine items using a scale ranging from (1) strongly disagree to (5) strongly agree. Sample items for vigor, dedication, and absorption subscales include "This afternoon at work, I felt strong and vigorous at my job", "This afternoon at work, I was proud of the work that I did", and "This afternoon at work, I got carried away when I was working" respectively. Using the three-factor structure, the average Cronbach's alpha across observations for vigor, dedication, and absorption were $.78, .67$, and .54 respectively.

Relational Energy was assessed using Owens et al.'s, (2016) Relational Energy Scale adapted for day-level measurement for this study. Participants were asked to indicate the extent to which they agreed with five items using a scale ranging from (1) strongly disagree to (5) strongly agree. Sample items for this scale include "This 
afternoon at work, I felt invigorated when I interacted with people" and "This afternoon at work, after interacting with people I felt more energy to do my work". The average Cronbach's alpha across observations was .83 .

\section{Analytic Approach}

Due to the nested nature of this type of data, I used hierarchical linear modeling with a mixed effects approach to test the study hypotheses. Day-level variables (i.e., energy management strategies, challenge and hindrance stressors) were person mean centered comparing each person's daily scores to the average of their daily scores. Fixed effects of the energy management strategies and outcomes were specified. In addition, fixed effects were also specified for all moderation hypotheses.

\section{Results}

\section{Preliminary Analyses}

\section{Missingness}

Missingness within the study sample was examined. A total of 26 participants had completed only the baseline survey whereas 109 participants completed the baseline and some daily surveys. These two groups were compared based on age, tenure, and hours worked per week. A dummy code was created in which the 26 participants with only baseline surveys were coded as 1 whereas participants with responses for the baseline and some daily surveys were coded as 0 . A series of independent $t$-tests were conducted to compare the two groups in age, tenure, and hours worked per week. Results demonstrated that there were no systematic differences between the two groups for age $(t(27.73)=-$ $1.03, n s)$, tenure $(t(26.68)=.36, n s)$, and hours worked per week $(t(26.15)=.11, n s)$. 
Multi-level confirmatory factor analyses (MCFA) of the nine-item version of the energy management scale (Parker et al., 2017) were conducted using Mplus version 8 (Muthén \& Muthén, 1998). The one-factor model chi-square value was significant, $\chi^{2}(54)$ $=428.72, \mathrm{p}<.001$, suggesting poor fit to the data. Alternative fit indices also suggested unacceptable fit, $\mathrm{CFI}=.74, \mathrm{TLI}=.65, \mathrm{SRMR}_{w}=13, \mathrm{SRMR}_{\mathrm{b}}=11, \mathrm{RMSEA}=.13 . \mathrm{A}$ three-factor model separating the different subscales demonstrated an improvement in fit, $\chi^{(}(48)=127.57, \mathrm{p}<.001, \mathrm{CFI}=.94, \mathrm{TLI}=.92, \mathrm{SRMR}_{w}=.09, \mathrm{SRMR}_{b}=.06, \mathrm{RMSEA}=$ .06. In addition, a comparison between the one-factor model and the three-factor model indicated that the three-factor model fit our data better, $\Delta \chi 2(6)=301.15$, $\mathrm{p}<.001)$.

We also ran a series of MCFAs to examine our study outcomes. Model 1 consisted of all items loaded on an overall factor and did not fit our data well, whereas Model 2 consisted of a five-factor structure (i.e., goal progress, vigor, dedication, absorption, relational energy) and yielded adequate fit, $\chi^{2}(208$ vs. 188$)=1453.22$ vs. $414.83, \mathrm{CFI}=.57$ vs. $.92, \mathrm{TFI}=.51$ vs. $.90, \mathrm{SRMR}_{\mathrm{w}}=.20$ vs. .06 , RMSEA $=.14$ vs. .06 , respectively for the two models. Most importantly, Model 2 fit the data significantly better than Model $1\left(\Delta \chi^{2}(20)=1038.39, \mathrm{p}<.001\right)$. Further, Model 3 consisted of a three-factor structure (i.e., goal progress, engagement, relational energy) and yielded an adequate fit, $\chi^{2}(202)=505.58, \mathrm{p}<.001, \mathrm{CFI}=.90, \mathrm{TLI}=.88, \mathrm{SRMR}_{w}=.07, \mathrm{RMSEA}=$ .07. A comparison between the five-factor model and the three-factor model indicated that the five-factor model fit our data better, $\left.\Delta \chi^{2}(14)=90.75, \mathrm{p}<.001\right)$.

\section{Hypothesis Testing}

Hypothesis 1 proposed that day-level organizing strategy use was positively related to day-level goal success. Results indicated that the use of organizing strategies 
was positively related to goal success $(\gamma=.19, S E=.07, p<.05)$, thus providing support for Hypothesis 1. Hypothesis 2 proposed that day-level meaning-making strategy use was positively related to day-level work engagement (e.g., vigor, dedication, and absorption). Results indicated that the use of meaning-making strategies was not related to vigor $(\gamma=$ $.06, S E=.08, n s)$, dedication $(\gamma=.11, S E=.06, n s)$, or absorption $(\gamma=-.09, S E=.06, n s)$. Thus, Hypothesis 2 was not supported. Hypothesis 3 proposed that day-level prosocial strategy use was positively related to day-level relational energy. Results indicated that the use of prosocial strategies was related to relational energy $(\gamma=.14, S E=.05, p<.05)$ indicating support for Hypothesis 3.

Hypotheses 4-6 examined the moderating effects of day-level challenge and hindrance stressors ${ }^{1}$. Hypothesis 4 a proposed that the relationship between day-level organizing strategy use and day-level goal progress will be stronger on days on which employees experience higher challenge stressors than on days with lower daily challenge stressors. Results indicated that the moderating effect of challenge stressors was not significant $(\gamma=-.02, S E=.16, n s)$, failing to support Hypothesis 4a. Hypothesis $4 \mathrm{~b}$ proposed that the positive relationship between day-level organizing strategy use and day-level goal progress will be weaker on days on which employees experience higher hindrance stressors than on days with lower hindrance stressors. Results indicated that hindrance stressors moderated the relationship between day-level organizing strategies and goal progress $(\gamma=.39, S E=.15, p<.01)$. Simple slopes tests were conducted to

\footnotetext{
${ }^{1}$ All moderation analyses were conducted while controlling for the other stressor. All results remained the same except for Hypothesis $5 \mathrm{~b}$ (meaning making strategies related to dedication moderated by hindrance stressors). Results indicated that without the inclusion of challenge stressors as a control, the interaction effect became marginally significant $(p=.05)$.
} 
further probe the nature of the interaction effect (Preacher, Curran, \& Bauer, 2006). As Figure 1 shows, the interaction pattern did not support our hypothesis as the positive relationship between day-level organizing strategy use and goal progress was weaker when employees experienced lower levels of hindrance stressors $(\gamma=.05, t=.63$, ns $)$, whereas this relationship was stronger when employees experienced higher levels of hindrance stressors. Therefore, hypothesis $4 \mathrm{~b}$ was not supported.

Hypothesis 5a proposed that the relationship between day-level meaning-making strategy use and day-level work engagement (e.g., vigor, dedication, absorption) will be stronger on days on which employees experience higher challenge stressors than on days with lower challenge stressors. Results indicated that the moderating effect of challenge stressors for the relationship between meaning-making strategies and vigor was not significant $(\gamma=.28, S E=.19, n s)$. However, results indicated that challenge stressors moderated the relationship between meaning making strategies and dedication $(\gamma=.49$, $S E=.15, p<.01)$ and absorption $(\gamma=.33, S E=.16, p<.05)$. Simple slopes tests were conducted to further probe the nature of each interaction effect (Preacher, Curran, \& Bauer, 2006). As Figure 2 shows, the interaction pattern supported our hypothesis as the positive relationship between day-level meaning-making strategy use and dedication was stronger when employees experienced higher levels of challenge stressors $(\gamma=.29, t=$ $3.77, \mathrm{p}<.001)$, whereas this relationship was weaker when employees experienced lower levels of challenge stressors $(\gamma=-.07, t=-.92, n s)$. As Figure 3 shows, the interaction pattern did not support our hypothesis as the positive relationship between day-level meaning-making strategy use and absorption was negative and stronger when employees experienced lower levels of challenge stressors $(\gamma=-.21, t=-2.58, p<.05)$, whereas this 
relationship was weaker when employees experienced higher levels of challenge stressors $(\gamma=.03, t=.39, n s)$. Taken together, Hypothesis 5a was partially supported indicating that daily challenge stressors were only a significant moderator for the relationship between day-level meaning making strategy use and dedication.

Hypothesis $5 \mathrm{~b}$ proposed that the relationship between day-level meaning-making strategies and day-level work engagement will be weaker on days on which employees experience higher hindrance stressors than on days with lower hindrance stressors. Results indicated that the moderating effect of hindrance stressors was not significant for the relationship between meaning making strategies and vigor $(\gamma=.07, S E=.18, n s)$ and absorption $(\gamma=.25, S E=.15, n s)$. However, results showed that daily hindrance stressors moderated the relationship between meaning-making strategies and dedication $(\gamma=.28$, $S E=.14, p<.05)$

Simple slopes tests were conducted to further probe the nature of the interaction effect (Preacher, Curran, \& Bauer, 2006). As Figure 4 shows, the interaction pattern did not support our hypothesis as the positive relationship between day-level meaning making strategy use and dedication was weaker when employees experienced lower levels of hindrance stressors $(\gamma=.03, t=.43, n s)$ whereas this relationship was stronger when employees experienced higher levels of hindrance stressors $(\gamma=.23, t=2.56, \mathrm{p}<$ $.05)$. Therefore, Hypothesis $5 \mathrm{~b}$ was not supported.

Hypothesis 6a proposed that the relationship between day-level prosocial strategies and day-level relational energy will be stronger on days on which employees experience higher challenge stressors than on days with lower daily challenge stressors. Results indicated that the moderating effect of challenge stressors was not significant $(\gamma=$ 
$-.03, S E=.11, n s)$, thus failing to support Hypothesis $6 \mathrm{a}$. Hypothesis $6 \mathrm{~b}$ proposed that the relationship between day-level prosocial strategies and day-level relational energy will be weaker on days on which employees experience higher hindrance stressors than on days with lower daily hindrance stressors. Results indicated that the moderating effect of challenge stressors was not significant $(\gamma=.15, S E=.15, n s)$, thus also failing to support Hypothesis 6b.

\section{Sensitivity Analyses}

All analyses were replicated using random slopes to test the study hypotheses ${ }^{2}$. Results indicated that day-level organizing strategy use and goal success were not significantly related $(\gamma=.12, S E=.09, n s)$. Further, day-level prosocial strategy use and relational energy were also not significantly related $(\gamma=.10, S E=.07, n s)$. Issues with statistical convergence were also present when testing Hypothesis 5a (i.e., vigor \& absorption) and Hypothesis 5 b (i.e., vigor \& absorption). Further analyses were conducted by adjusting individual slopes to vary randomly. Overall, the results remained the same when allowing the control and moderator variable slopes to vary and the slope variance remained non-significant, therefore justifying the use of fixed slopes.

\section{Discussion}

\section{Theoretical Implications}

These findings offer several important insights into the literature on work-related energy management strategies. First, past research on work-related energy management strategies has suffered from the use of weaker research designs such as the use of cross-

\footnotetext{
${ }^{2}$ All results remained the same unless otherwise noted.
} 
sectional surveys. By implementing a daily diary design, we were able to test which strategies were most effective for momentary gains associated with the use of each workrelated energy management strategy and examine how fluctuations in daily stressors influenced these relationships. Second, there is limited research as to whether certain strategies are associated with unique outcomes for employees. Findings from this study also suggest that it may be advantageous to use specific strategies under certain circumstances as some of the work-related energy management strategies were found to be related to different employee outcomes when daily challenge and hindrance stressors were at a certain level.

Our results suggest that engaging in organizing behaviors such as making to-do lists, setting new goals, and checking and updating your schedule in the morning is linked to higher goal success that day. This finding is in line with COR Theory's Investment Principle suggesting that investing in organizing strategies increases concentration, expands one's capacity to invest effort into completing one's work, and is associated with important resources such as self-efficacy or motivation that aids in the further competition of one's goals that day (Hobfoll et al., 2018; Parker et al., 2017). This finding is also consistent with prior research on the benefits of reattachment, or the process of 'mentally reconnecting' to work in the morning (Sonnentag \& Kunhel, 2016). Organizing strategies represent specific workplace behaviors that employees can utilize in order to facilitate the reattachment process. Specifically, these behaviors allow employees to mobilize their energy accordingly by directing one's attention to important work tasks that day (Sonnentag \& Kunhel, 2016). Furthermore, by thinking about and preparing for the upcoming workday through the use of these strategies, one can mobilize 
their resources as needed thereby linking the use of these behaviors to higher goal success that day (Sonnentag \& Kunhel, 2016).

We also examined whether daily challenge stressors would moderate the direct relationship between day-level organizing strategy use and goal progress. However, we found no significant interaction effect of challenge stressors on this relationship. A possible explanation is that the moderating effect of challenge stressors vary depending on the specific challenge stressor. For example, time pressure, a common challenge stressor, is defined as the perception of an inadequate amount of time required to complete work related tasks (Kinicki \& Vecchio, 1994). Under higher levels of time pressure, the use of certain organizing strategies such as creating to-do lists may actually exacerbate the perceived demands (e.g., workload) required to accomplish one's goals that day (Parker et al., 2018). Therefore, under higher time pressure, the use of these strategies may be overwhelming and goal progress may suffer. In contrast, on days with higher workload, the use of certain strategies such as daily goal setting may actually benefit goal progress. Goal setting behaviors help direct one's attention and effort toward goal-relevant activities and away from goal irrelevant activities thereby leading to higher goal progress that day (Locke \& Latham, 2002). Taken together, this may suggest that the moderating effects of challenge stressors on the relationship between organizing strategy use and goal progress is more complex than initially assumed. For this reason, researchers should examine the unique effects of specific challenge stressors since testing the effects of these stressors together may wash out potential moderation effects.

Contrary to expectation, we found that the relationship between organizing strategies and goal progress and meaning-making strategies and dedication was stronger 
on days with higher (as opposed to lower) levels of daily hindrance stressors. Although the pattern of these interaction effects was not in line with our study hypotheses, together these findings suggest the presence of an over-compensation effect. In other words, when faced with higher levels of daily hindrance stressors, individuals attempt to offset the anticipated losses in energy through enacting a greater use of organizing and meaningmaking energy management strategies at work. In all, these findings suggest that when employees anticipated higher levels of stressors on a given workday, they relied on these energy management strategies even more in order to proactively neutralize or recoup potential losses in energy stemming from experiencing higher hindrance stressors that workday.

Similar to Parker et al.'s (2017) day-level study on work-related energy management strategies, we found no main effects of meaning-making strategy use on our study outcomes. Some researchers have called into question the temporal dynamics associated with specific meaning-making behaviors such as positive work reflection (Parker et al., 2017). On one hand, some research has found immediate benefits associated with positive work reflection, such that on days which individuals engaged in positive work reflection, they reported decreased stress, physical and mental health complaints, and increased psychological detachment that evening (Bono, Glomb, Shen, Kim, and Koch, 2013), increased serenity at bedtime, and decreased depressive mood at bedtime and the next morning (Meier, Cho, \& Dumani, 2016). On the other hand, one intervention study found that positive work reflection was not associated with enhanced well-being (Meier et al., 2016). In part, the researchers argued that the duration of the intervention may have been too short to find intervention effects (Meier et al., 2016). 
Thus, the former research findings demonstrate the immediate benefits associated with positive work reflection, whereas the latter findings point to the potential for delayed benefits associated with positive work reflection. However, our study reconciles these inconsistent findings. In line with past findings on the immediate benefits of positive work reflection, our study findings revealed that on days with higher challenge stressors, the positive relationship between meaning-making strategies and dedication was stronger. Therefore, this finding suggests that challenge stressors serve as an important moderator further elucidating when positive work reflection is associated with immediate benefits for individuals.

We also found that day-level meaning-making strategies were negatively (as opposed to positively) related to absorption when employees experienced lower levels of challenge stressors. In line with the Challenge and Hindrance Stressor Framework, higher levels of challenge stressors should foster a host of opportunities for personal gain such as growth and development at work (LePine et al., 2005). In contrast, opportunities for personal gain become less salient under conditions characterized by lower challenge stressors. Therefore, when individuals use meaning-making strategies under lower levels of challenge stressors, this may be associated with decreased feelings of absorption at work because opportunities to advance and attain valued work outcomes are not as salient for individuals. Thus, under lower challenge stressors, the relationship between meaningmaking strategy use might be negatively related to absorption as opposed to positively related to absorption.

We also examined whether challenge and hindrance stressors would moderate the relationship between meaning-making strategies and vigor. Despite the view that 
challenge stressors are "beneficial" stressors linked to positive outcomes, this perspective may be too simplistic. We argue that in order to better observe the impact of these stressors, researchers should examine individual challenge stressors. For example, having the responsibility to help others at work may be a positive boundary condition. Under these conditions, using positive work reflection may lead individuals to feel energized as they reflect on the positive impact they have had on others at work. In contrast, too high of workload may be a negative boundary condition. Thus, under this time constraint, individuals may be less likely to engage in meaning-making strategies (e.g., positive work reflection) and therefore experience lower levels of vigor. In all, studying the unique effects of specific challenge stressors as boundary conditions may provide a more nuanced understanding of when we will observe the benefits of these stressors.

Similarly, we found no interaction effect of hindrance stressors on the relationship between meaning-making strategies and vigor. We argue that social support from coworkers and/or supervisors may be an additional moderator of this relationship. Higher levels of social support may help further buffer the negative effects of hindrance stressors. Past research has found evidence indicating that social support can serve an important buffer against negative outcomes in the workplace (Bakker, Demerouti, \& Euwema, 2005). In line with COR Theory (Hobfoll et al., 2018), those with greater resources are less vulnerable to resource loss and are more likely to gain resources. Therefore, social support is a critical resource that may buffer against further resource loss. Further, under these conditions, we may see individuals reap the benefits of using these strategies even under higher levels of hindrance stressors if properly supported by others. 
Past research has often neglected to consider the importance of positive relationships in the workplace by "[placing them] in the background of organizational life" (Dutton \& Ragins, 2007, p. 5). However, in support of COR Theory, we found that individuals can replenish important limited resources such as energy, through engaging in positive social interactions with others (Hobfoll et al., 2018). Specifically, we found that engaging in prosocial behaviors such as showing gratitude, offering help, and going out of one's way to make others happy is associated with higher levels of relational energy that day. Other past day-level research also supports this perspective such that engaging in altruistic behaviors at work were found to have energizing effects (Fu Lam, Wan, \& Roussin, 2016).

Finally, we also examined whether the relationship between prosocial strategy use and relational energy would be moderated by both challenge and hindrance stressors. Our results indicated that neither challenge nor hindrance stressors were significant moderators of this relationship. To explain the non-significant moderating effect of each stressor, we turn to past research on helping behaviors in the workplace. Research findings regarding the benefits associated with prosocial behaviors in the workplace are mixed. On the one hand, much research has focused on benefits associated with these behaviors as some day-level findings point to the energizing effects of prosocial behaviors (Lan et al., 2016; Weinstein \& Ryan, 2010). On the other hand, some research evidence suggests that these behaviors can be depleting and can actually be a cost to the helper (Lanaj, Johnson, \& Wang, 2016). For this reason, it may be difficult to predict how challenge and hindrance stressors will differentially interact with the use of prosocial strategies. A possible explanation for the lack of moderation effects could be presence or 
lack of certain condition resources, namely work autonomy (Hobfoll et al., 2018). Specifically, work scheduling autonomy (WSA) may be a critical condition resource where those with higher in WSA have the latitude and means to "go out of their way" to help others while working under both challenge and hindrance stressors. Therefore, WSA may be an additional moderator of this relationship elucidating certain boundary conditions under which the benefits of prosocial behaviors are best understood.

\section{Practical Implications}

These study findings have implications regarding how employees can best manage their energy in the workplace. First, employees should seek to engage in organizing strategies on a daily basis and earlier in the morning, as these behaviors are associated with performance outcomes such as higher levels of goal progress and daily work engagement (Sonnentag \& Kunhel, 2016; Sonnentag, Eck, Fritz, \& Kuhnel, 2019). Employees should not only seek to engage in these organizing behaviors early in the morning, but recent research has also pointed to the importance of establishing and maintaining morning routines as these were associated with higher goal success as well (McClean, Koopman, Yim, \& Klotz, 2020).

Whereas past research has found mixed effects associated with prosocial behaviors, our study results indicated that these behaviors in the workplace are energizing. Therefore, employees should seek more opportunities that allow them to engage positively with others at work. Most importantly, these daily behaviors are associated with increased feelings of closeness or camaraderie among coworkers. In this way, the benefits of these prosocial behaviors should not be overlooked and illustrate that taking time to go out of one's way to engage with others in a positive and altruistic 
manner is associated with energizing effects which helps foster a more positive workplace environment.

Finally, employees who use meaning-making strategies should also experience greater dedication at work when working under conditions of higher challenge stressors. Therefore, individuals who choose to use these particular strategies may also benefit from recognizing when they are working under such conditions or purposefully seek opportunities that foster growth and challenge the individual at work (Le Pine et al., 2005).

\section{Limitations and Future Directions}

Although this study has several strengths, it is not without limitations. First, from a methodological perspective, this study suffers from common method bias as we only relied on self-report data (Podsakoff, MacKenzie, Lee, \& Podsakoff, 2003). Future research should utilize other reported or objective measures when assessing constructs such as relational energy and performance outcomes. Specifically, future research on relational energy would benefit from collecting data from dyads as this approach would provide a fine-grained examination of the energizing processes shared between two people (e.g., helper and receiver).

Second, we were only able to capture a limited sample of behaviors as part of each work-related strategy. While the literature on best practices for experience sampling studies advocate for the use of the shortest scales (Gabriel et al., 2019), past research has suggested that employees manage their energy in a plethora of ways (e.g., seeking feedback, switching to another task) (Fritz et al., 2011; Zacher et al., 2014). In a similar vein, researchers have started to examine the positive outcomes associated with micro- 
breaks (i.e., temporary breaks unrelated to work) as another form of energy management at work (Hunter \& Wu, 2015; Kim et al., 2017; Kim et al., 2018). Therefore, future research should examine a broader range of energy management strategies and behaviors concurrently in order to better understand the many ways in which people conserve and boost their energy levels at work.

Third, while we examined the moderating effect of a variety of challenge and hindrance stressors, future research would benefit from focusing on more specific challenge or hindrance stressors as moderators of these relationships. Based on item statistics, it was clear that certain stressors were more frequently encountered than others. For example, the item I felt there were clear goals and objectives for my work (reverse coded) was one of the highest reported hindrance stressors. This particular hindrance stressor may be especially detrimental for the use of organizing strategies on goal progress as employees are unsure of how to best utilize these specific strategies in order to achieve higher goal progress that day. Further, this particular hindrance stressor may also serve as an impediment to the use of meaning-making strategies and work engagement, as one is uncertain about their role and greater purpose at work.

Finally, while the current research design allowed us to investigate the momentary or short-term benefits associated with work-related energy management strategy use, the long-term benefits associated with these strategies were not examined. Longitudinal methods would allow us to look at the potential delayed effects of energy management strategies across several days or weeks. Further, future research on these strategies would benefit from utilizing a longitudinal design as suggested by COR Theory’s Resource Gain Spiral Corollary (Hobfoll et al., 2018). This research design would allow for the 
examination of gain spirals over longer periods of time, as this design provides ample time to investigate the potential upward or resource gain spirals that may unfold over the course of several weeks (Hobfoll et al., 2018).

\section{Conclusion}

Human energy must be managed effectively in order to maintain higher levels of well-being at work. In this study, we contributed to the literature on energy management by showing that investing in specific work-related energy management strategies is associated with unique performance and wellbeing outcomes at work. Most importantly, our findings suggest that employees would benefit from selecting the strategy according to specific daily work conditions (e.g., higher/lower challenge/hindrance stressors).

Further, based on these findings, employees should seek daily opportunities to invest in work-related energy management strategies in order to sustain and bolster one's energy at work. 


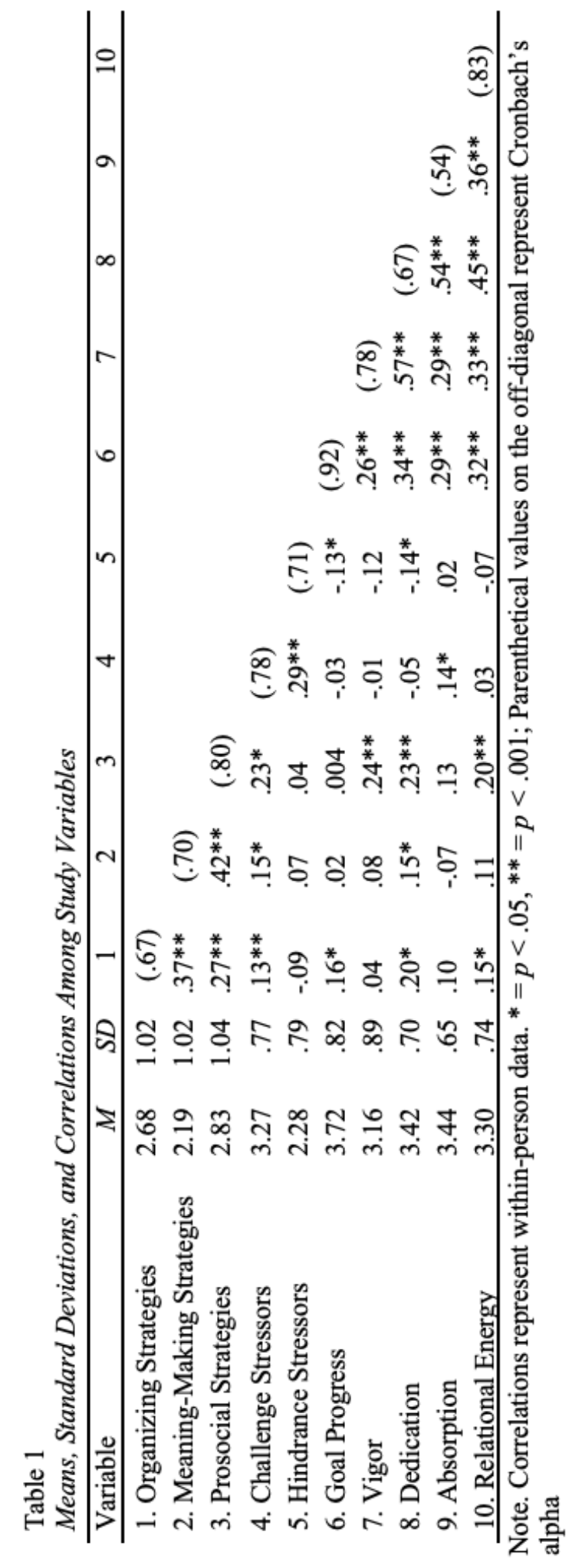




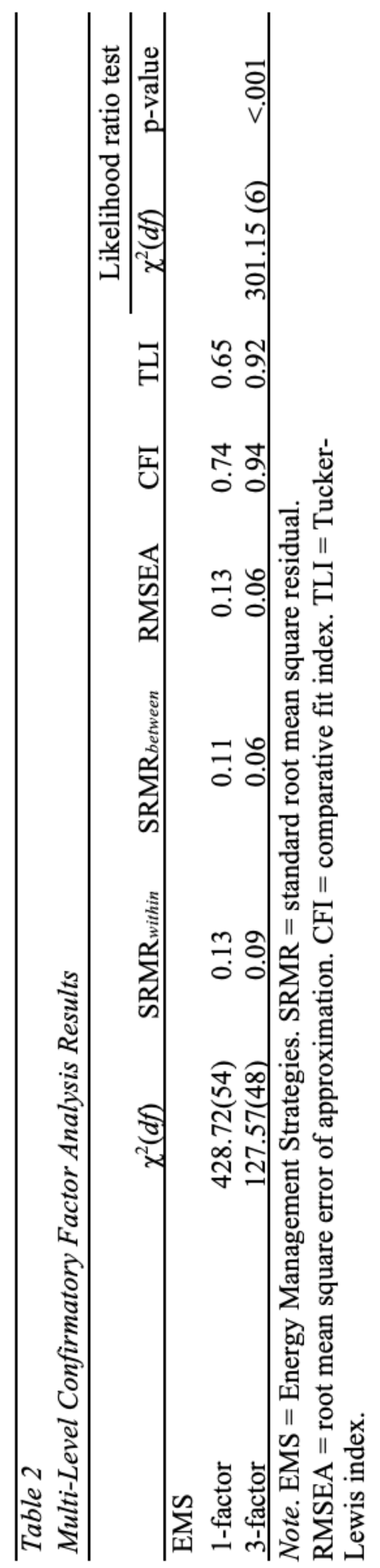


Table 3. Moderating effect of challenge stressors and organizing strategies on goal progress Goal Progress Coefficient $S E$

\begin{tabular}{lll}
\hline Intercept & $3.74 * * *$ & .07 \\
Hindrance Stressors & -.14 & .11 \\
Organizing Strategies & $.18^{*}$ & .07 \\
Challenge Stressors & -.04 & .10 \\
Organizing Strategies x Challenge Stressors & -.02 & .16 \\
\hline
\end{tabular}

$N=109 . \mathrm{N}_{\text {obs }}$ ranged from $237-404$ for the analysis.

$* \mathrm{p}<.05 ; * * \mathrm{p}<.01 ; * * * \mathrm{p}<.001$.

Table 4. Moderating effect of hindrance stressors and organizing strategies on goal progress

\begin{tabular}{lll}
\hline & \multicolumn{2}{c}{ Goal Progress } \\
\cline { 2 - 3 } & Coefficient & $S E$ \\
\hline Intercept & $3.74 * * *$ & .07 \\
Challenge Stressors & -.02 & .10 \\
Organizing Strategies & $.19 * *$ & .07 \\
Hindrance Stressors & -.19 & .11 \\
Organizing Strategies x Hindrance Stressors & $.39 * *$ & .14 \\
\hline
\end{tabular}

$N=109$. $\mathrm{N}_{\text {obs }}$ ranged from $237-404$ for the analysis.

$* \mathrm{p}<.05 ; * * \mathrm{p}<.01 ; * * * \mathrm{p}<.001$. 


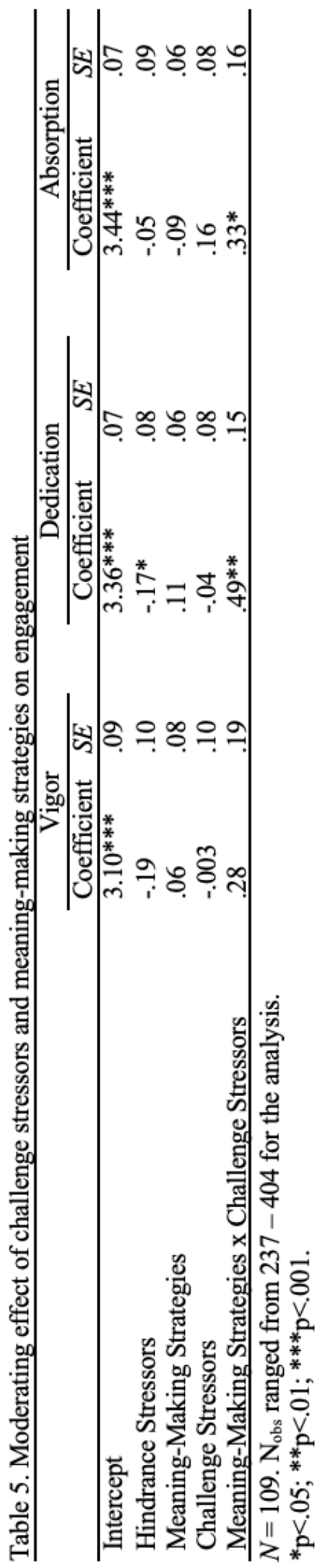




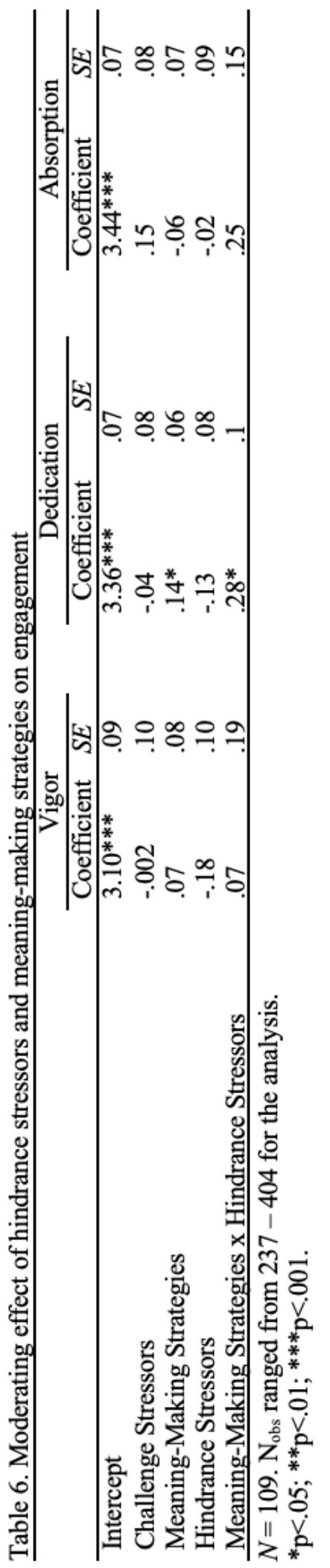


Table 7. Moderating effect of challenge stressors and prosocial strategies on relational energy

\begin{tabular}{lll}
\hline & \multicolumn{2}{l}{ Relational Energy } \\
\cline { 2 - 3 } & Coefficient & $S E$ \\
\hline Intercept & $3.29 * * *$ & .08 \\
Hindrance Stressors & -.09 & .09 \\
Prosocial Strategies & $.14^{* *}$ & .05 \\
Challenge Stressors & .00 & .10 \\
Prosocial Strategies x Challenge Stressors & -.03 & .11 \\
\hline
\end{tabular}

$N=109$. Nobs ranged from $237-404$ for the analysis.

$* \mathrm{p}<.05 ; * * \mathrm{p}<.01 ; * * * \mathrm{p}<.001$.

Table 8. Moderating effect of hindrance stressors and prosocial strategies on relational energy

\begin{tabular}{lll}
\hline & \multicolumn{2}{l}{ Relational Energy } \\
\cline { 2 - 3 } & Coefficient & $S E$ \\
\hline Intercept & $3.28 * * *$ & .08 \\
Challenge Stressors & .02 & .09 \\
Prosocial Strategies & $.14^{* *}$ & .05 \\
Hindrance Stressors & -.11 & .10 \\
Prosocial Strategies x Hindrance Stressors & .16 & .15 \\
\hline
\end{tabular}

$N=109$. Nobs ranged from $237-404$ for the analysis.

$* \mathrm{p}<.05 ; * * \mathrm{p}<.01 ; * * * \mathrm{p}<.001$. 


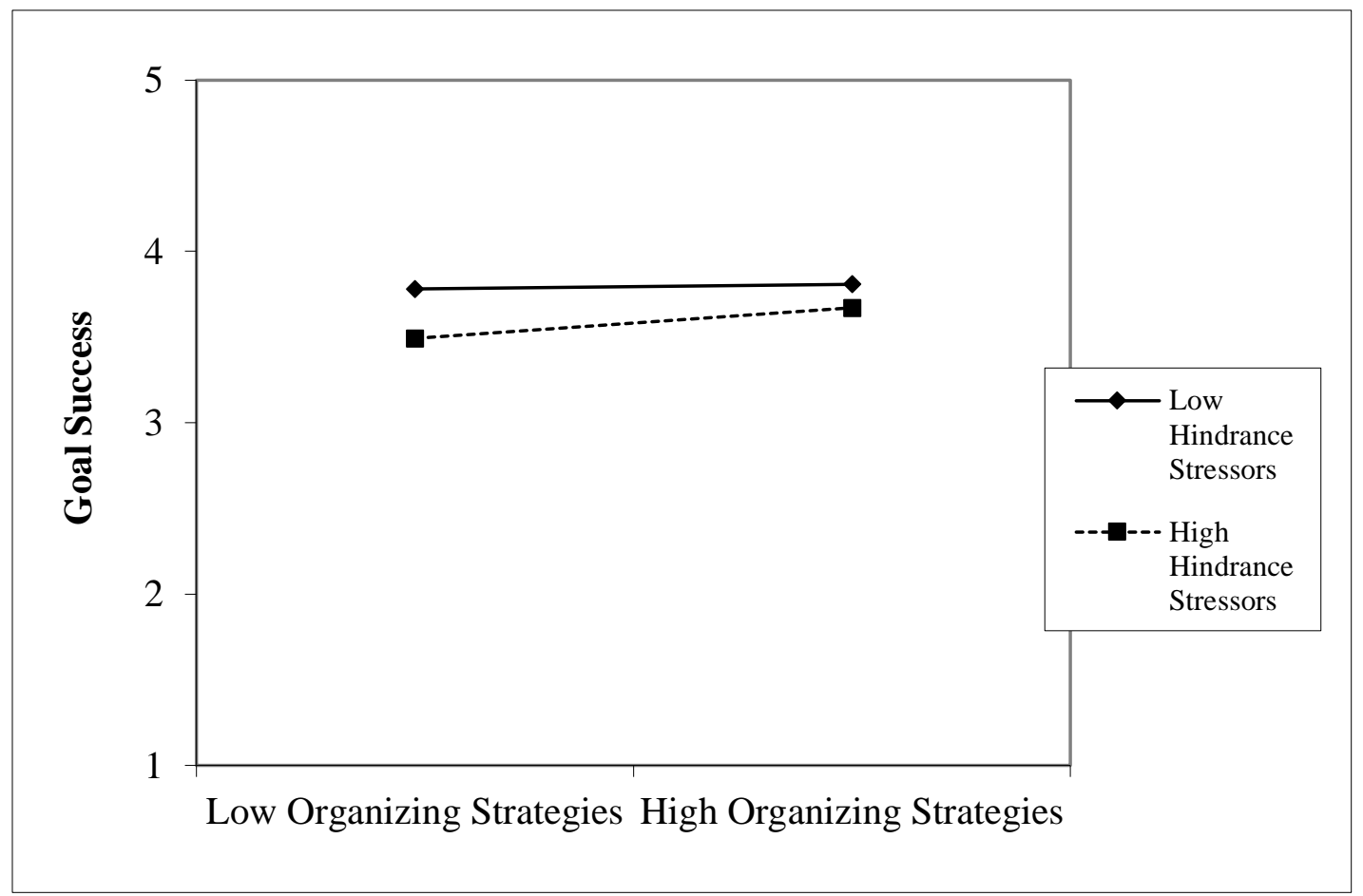

Figure 1: Graphic representation of the interaction between organizing strategies and hindrance stressors in predicting goal progress. 


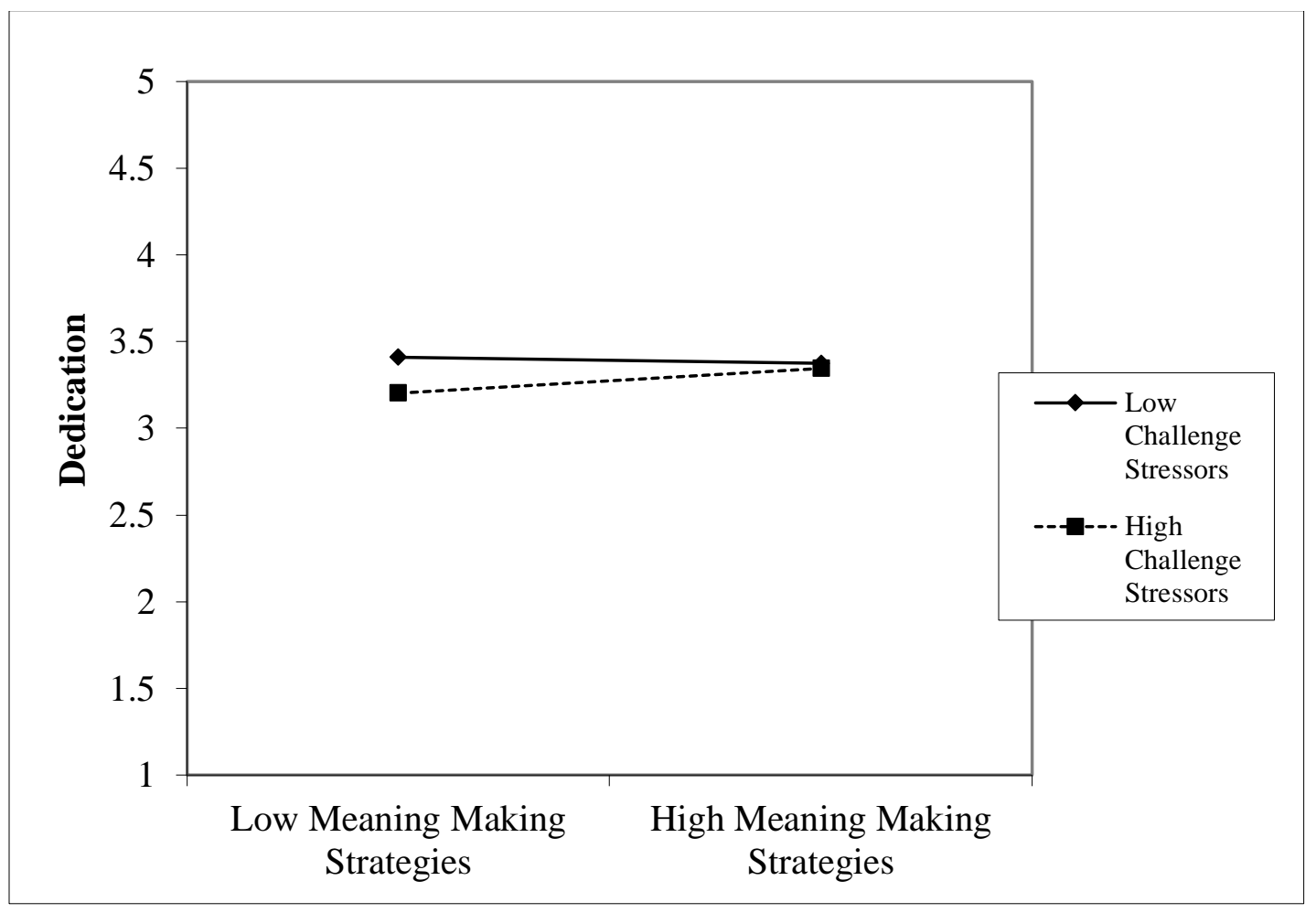

Figure 2: Graphic representation of the interaction between meaning-making strategies and challenge stressors in predicting dedication. 


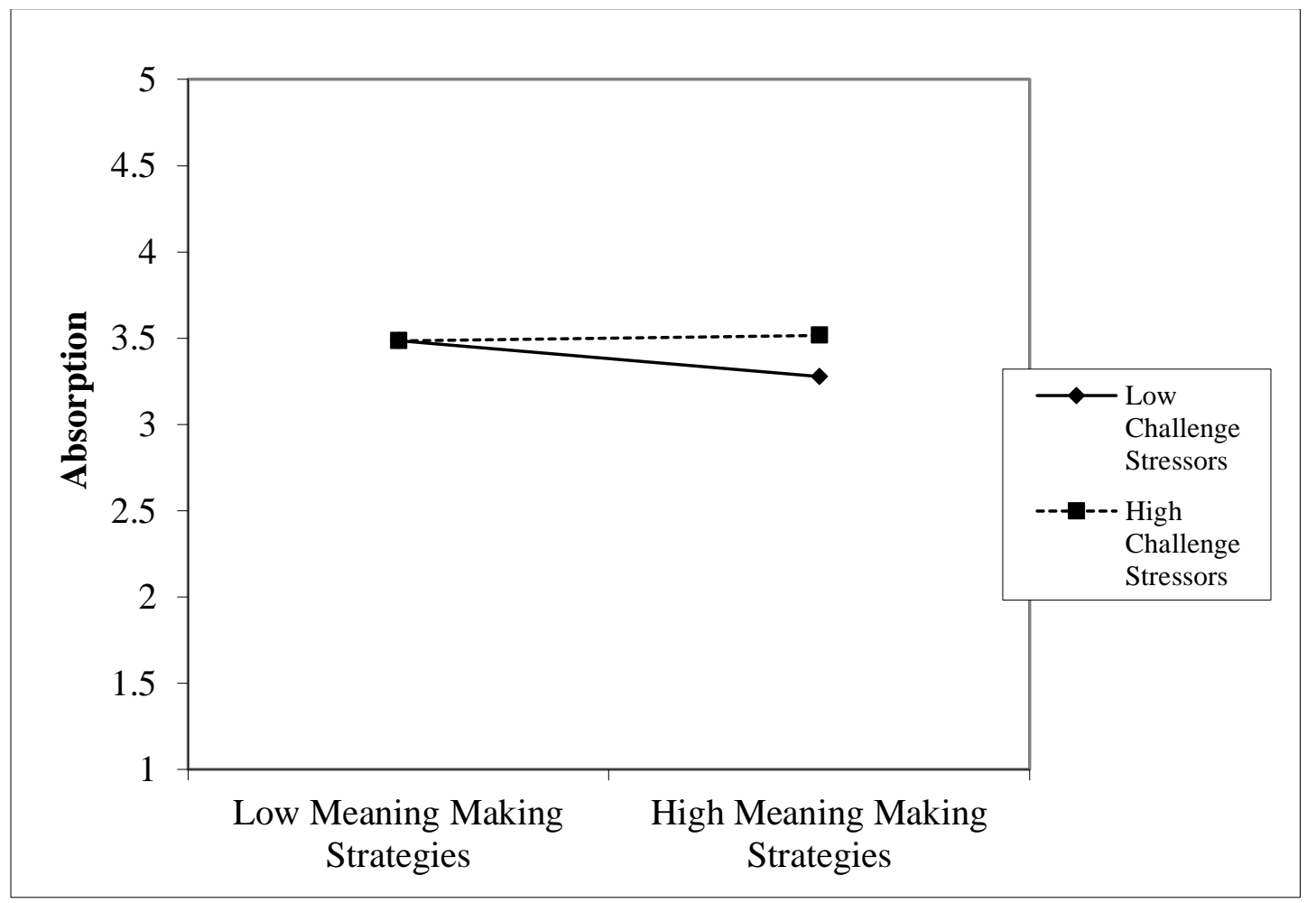

Figure 3: Graphic representation of the interaction between meaning-making strategies and challenge stressors in predicting absorption. 


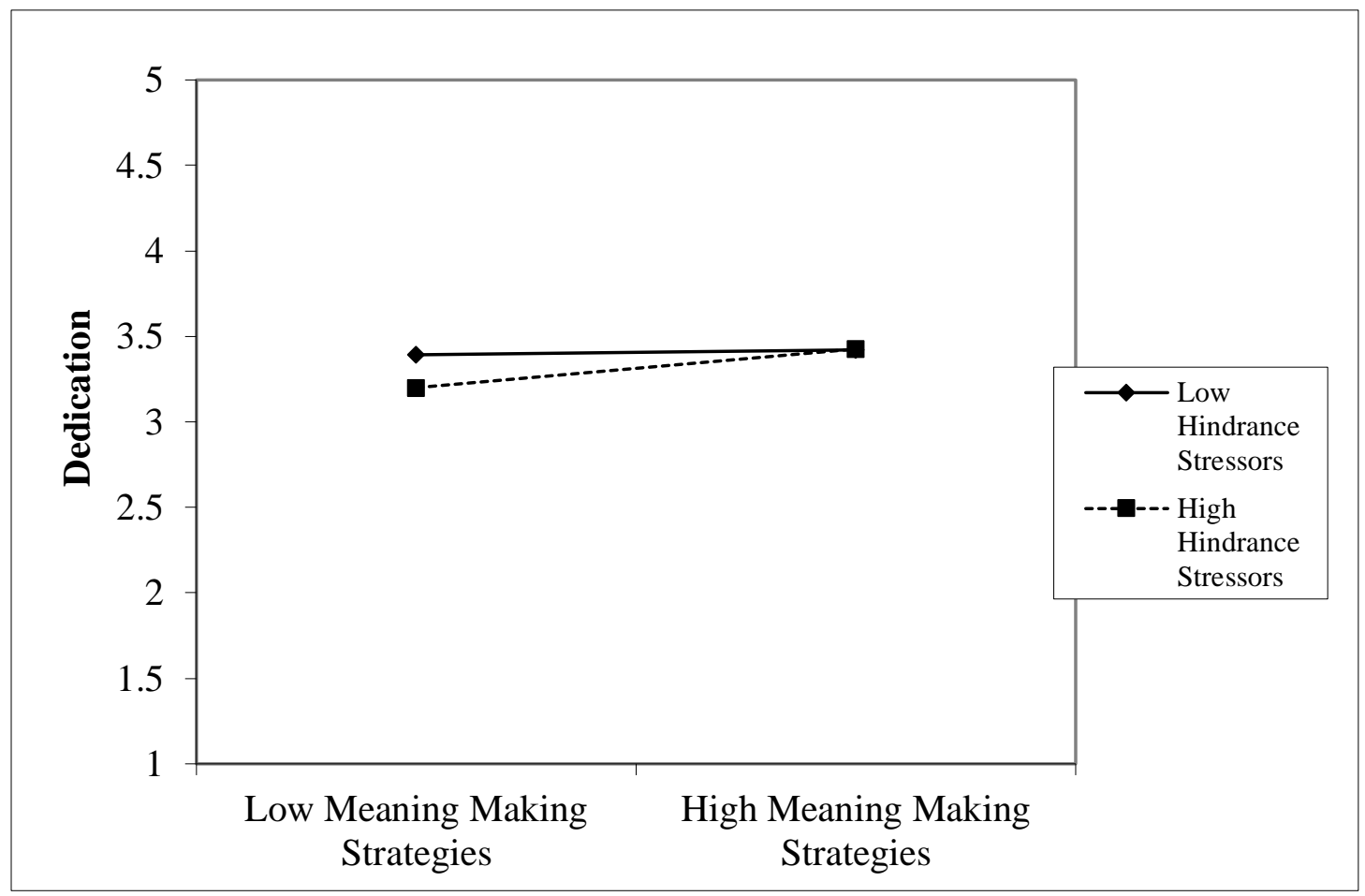

Figure 4: Graphic representation of the interaction between meaning-making strategies and hindrance stressors in predicting dedication. 


\section{References}

Baker, W. E. (2019). Emotional energy, relational energy, and organizational energy: toward a multilevel model. Annual Review of Organizational Psychology and Organizational Behavior, 6, 373-395. https://doi.org/10.1146/annurev-orgpsych012218-015047

Bakker, A. B. (2014). Daily fluctuations in work engagement: An overview and current directions. European Psychologist, 19, 227-236. https://doi.org/10.1027/1016$9040 / \mathrm{a} 000160$

Bakker, A. B., Demerouti, E., \& Euwema, M. C. (2005). Job Resources Buffer the Impact of Job Demands on Burnout. Journal of Occupational Health Psychology, 10, 170-180. https://doi.org/10.1037/1076-8998.10.2.170

Bono, J. E., Glomb, T. M., Shen, W., Kim, E., \& Koch, A. J. (2013). Building positive resources: Effects of positive events and positive reflection on work stress and health. Academy of Management Journal, 56, 1601-1627. https://doi.org/10.5465/amj.2011.0272

Breevaart, K., Bakker, A. B., Demerouti, E., \& Hetland, J. (2012). The measurement of state work engagement: A multilevel factor analytic study. European Journal of Psychological Assessment, 28, 305-312. http://dx.doi.org/10.1027/1015$5759 / \mathrm{a} 000111$

Cavanaugh, M. A., Boswell, W. R., Roehling, M. V., \& Boudreau, J. W. (2000). An empirical examination of self-reported work stress among US managers. Journal of Applied Psychology, 85, 65-74. https://doi.org/10.1037/0021-9010.85.1.65 
Crawford, E. R., LePine, J. A., \& Rich, B. L. (2010). Linking job demands and resources to employee engagement and burnout: a theoretical extension and meta-analytic test. Journal of Applied Psychology, 95, 834 - 848. https://doi.org/10.1037/a0019364

de Bloom, J., Kinnunen, U., \& Korpela, K. (2015). Recovery processes during and after work: Associations with health, work engagement, and job performance. Journal of Occupational and Environmental Medicine, 57, 732-742.

https://doi.org/10.1097/JOM.0000000000000475

Dutton, J. E., \& Ragins, B. R. (Eds.). (2007). Exploring positive relationships at work: Building a theoretical and research foundation. Lawrence Erlbaum Associates Publishers.

Fairlie, P. (2011). Meaningful work, employee engagement, and other key employee outcomes: Implications for human resource development. Advances in Developing Human Resources, 13, 508-525.

https://doi.org/10.1177/1523422311431679

Folkman, S., \& Lazarus, R.S. (1990) Coping and emotion. In N.L. Stein, B. Leventhal, \& T. Trabasso (Eds.), Psychological and biological approaches to emotion (pp. 313 -332). Hillsdale, NJ: Erlbaum.

Fritz, C., Lam, C. F., \& Spreitzer, G. M. (2011). It's the little things that matter: An examination of knowledge workers' energy management. Academy of Management Perspectives, 25, 28-39. https://doi.org/10.5465/AMP.2011.63886528

Fu Lam, C., Wan, W. H., and Roussin, C. J. (2016). Going the extra mile and feeling 
energized: an enrichment perspective of organizational citizenship behaviours. Journal of Applied Psychology, 101, 379-391. doi: 10.1037/ap10000071

Gabriel, A. S., Podsakoff, N. P., Beal, D. J., Scott, B. A., Sonnentag, S., Trougakos, J. P., \& Butts, M. M. (2019). Experience Sampling Methods: A Discussion of Critical Trends and Considerations for Scholarly Advancement. Organizational Research Methods, 22, 969-1006. https://doi.org/10.1177/1094428118802626

Geldenhuys, M., Laba, K., \& Venter, C. M. (2014). Meaningful work, work engagement and organisational commitment. SA Journal of Industrial Psychology, 40, 1-10. doi:10.4102/sajip.v40i1.1098

Harris, K. J., Harvey, P., \& Kacmar, K. M. (2009). Do social stressors impact everyone equally? An examination of the moderating impact of core self-evaluations. Journal of Business and Psychology, 24, 153-164. https://doi.org/10.1007/s10869-009-9096-2

Hobfoll, S. E. (1989). Conservation of resources: A new attempt at conceptualizing stress. American psychologist, 44, 513-524. https://doi.org/10.1037/0003066X.44.3.513

Hobfoll, S. E., Halbesleben, J., Neveu, J. P., \& Westman, M. (2018). Conservation of resources in the organizational context: The reality of resources and their consequences. Annual Review of Organizational Psychology and Organizational Behavior, 5, 103-128.https://doi.org/10.1146/annurev-orgpsych-032117-104640

Hunter, E. M., \& Wu, C. (2016). Give me a better break: Choosing workday break activities to maximize resource recovery. Journal of Applied Psychology, 101, 302-311. http://dx.doi.org/10.1037/ap10000045 
Kahn, W. A. (1990). Psychological conditions of personal engagement and disengagement at work. Academy of Management Journal, 33, 692-724. https://doi.org/10.2307/256287

Kim, S., Park, Y., \& Headrick, L. (2018). Daily micro-breaks and job performance: General work engagement as a cross-level moderator. Journal of Applied Psychology, 103, 772-786. https://doi.org/10.1037/ap10000308

Kim, S., Park, Y., \& Niu, Q. (2017). Micro-break activities at work to recover from daily work demands. Journal of Organizational Behavior, 38, 28-44. https://doi.org/10.1002/job.2109

Kinicki, A.J. \& Vecchio, R.P. (1994). Influences on the quality of supervisor-subordinate relations: The role of time pressure, organizational commitment, and locus of control. Journal of Organizational Behavior, 15, 75-82. https://doi.org/10.1002/job.4030150108

Lanaj, K., Johnson, R. E., \& Wang, M. (2016). When lending a hand depletes the will: The daily costs and benefits of helping. Journal of Applied Psychology, 101, 1097-1110. https://doi.org/10.1037/ap10000118

LePine, J. A., LePine, M. A., \& Jackson, C. L. (2004). Challenge and Hindrance Stress: Relationships with Exhaustion, Motivation to Learn, and Learning Performance. Journal of Applied Psychology, 89, 883-891. http://dx.doi.org/10.1037/0021-9010.89.5.883

LePine, J. A., Podsakoff, N. P., \& LePine, M. A. (2005). A meta-analytic test of the challenge stressor-hindrance stressor framework: An explanation for inconsistent 
relationships among stressors and performance. Academy of Management Journal, 48, 764-775. https://doi.org/10.5465/AMJ.2005.18803921

Locke, E. A., \& Latham, G. P. (2002). Building a practically useful theory of goal setting and task motivation: A 35-year odyssey. American Psychologist, 57, 705 717. https://doi.org/10.1037/0003-066X.57.9.705

Low, R. S. T., Overall, N. C., Hammond, M. D., \& Girme, Y. U. (2017). Emotional suppression during personal goal pursuit impedes goal strivings and achievement. Emotion, 17, 208-223. https://doi.org/10.1037/emo0000218

May, D. R., Gilson, R. L., \& Harter, L. M. (2004). The psychological conditions of Meaningfulness, safety and availability and the engagement of the human spirit at work. Journal of Occupational and Organizational Psychology, 77, 11-37. https://doi.org/10.1348/096317904322915892

McClean, S. T., Koopman, J., Yim, J., \& Klotz, A. (In press) Stumbling out of the Gate: The energy-based implications of morning routine disruption. Personnel Psychology. https://doi.org/10.1111/peps.12419

Meier, L. L., Cho, E., \& Dumani, S. (2016). The effect of positive work reflection during leisure time on affective well-being: Results from three diary studies. Journal of Organizational Behavior, 37, 255-278. https://doi.org/10.1002/job.2039

Owens, B. P., Baker, W. E., Sumpter, D. M., \& Cameron, K. S. (2016). Relational energy at work: Implications for job engagement and job performance. Journal of Applied Psychology, 101, 35-49. http://dx.doi.org/10.1037/apl0000032

Parker, S. L., Zacher, H., de Bloom, J., Verton, T. M., \& Lentink, C. R. (2017). Daily use of energy management strategies and occupational well-being: The moderating 
role of job demands. Frontiers in Psychology, 8, 1-12.

https://doi.org/10.3389/fpsyg.2017.01477

Podsakoff, N. P., LePine, J. A., \& LePine, M. A. (2007). Differential challenge stressorhindrance stressor relationships with job attitudes, turnover intentions, turnover, and withdrawal behavior: A meta-analysis. Journal of Applied Psychology, 92, 438-454. http://dx.doi.org/10.1037/0021-9010.92.2.438

Podsakoff, P. M., MacKenzie, S. B., Lee, J. Y., \& Podsakoff, N. P. (2003). Common method biases in behavioral research: A critical review of the literature and recommended remedies. Journal of Applied Psychology, 88, 879-903. https://doi.org/10.1037/0021-9010.88.5.879

Pratt, M. G., Ashforth, B. E. (2003). Fostering meaningfulness in working and in work. In Cameron, K. S., Dutton, J. E., Quinn, R. E. (Eds.), Positive organizational scholarship: Foundations of a new discipline (pp. 309-327). San Francisco, CA: Barrett-Koehler.

Preacher, K. J., Curran, P. J., \& Bauer, D. J. (2006). Computational tools for probing interactions in multiple linear regression, multilevel modeling, and latent curve analysis. Journal of Educational and Behavioral Statistics, 31, 437-448.

Rodell, J. B., \& Judge, T. A. (2009). Can "good" stressors spark "bad" behaviors? The mediating role of emotions in links of challenge and hindrance stressors with citizenship and counterproductive behaviors. Journal of Applied Psychology, 94, 1438-1451. http://dx.doi.org/10.1037/a0016752

Rosso, B. D., Dekas, K. H., \& Wrzesniewski, A. (2010). On the meaning of work: A 
theoretical integration and review. Research in organizational behavior, 30, 91127. https://doi.org/10.1016/j.riob.2010.09.001

Schaufeli,W. B.,\& Bakker,A.B. (2010). Defining and measuring work engagement: Bringing clarity to the concept. In M. P. Leiter \& A.B. Bakker (Eds.), Work engagement: A handbook of essential theory and research (pp. 10-24). NewYork: Psychology Press.

Schaufeli, W. B., Bakker, A. B., \& Salanova, M. (2006). The measurement of work engagement with a short questionnaire: A cross-national study. Educational and Psychological Measurement, 66, 701-716.

https://doi.org/10.1177/0013164405282471

Schaufeli, W. B., Salanova, M., González-Romá, V., \& Bakker, A. B. (2002). The measurement of burnout and engagement: A confirmatory factor analytic approach. Journal of Happiness Studies, 3, 71-92.

https://doi.org/10.1023/A:1015630930326

Shraga, O., \& Shirom, A. (2009). The construct validity of vigor and its antecedents: A qualitative study. Human Relations, 62, 271-291. https://doi.org/10.1177/0018726708100360

Sonnentag, S., Dormann, C., \& Demerouti, E. (2010). Not all days are created equal: The concept of state work engagement. In A. B. Bakker \& M. P. Leiter (Eds.), Work engagement: A handbook of essential theory and research (pp. 25-38). New York, NY: Psychology Press. 
Sonnentag, S., Eck, K., Fritz, C., \& Kühnel, J. (2019). Morning Reattachment to Work and Work Engagement During the Day: A Look at Day-Level Mediators. Journal of Management. https://doi.org/10.1177/0149206319829823

Sonnentag, S., \& Kühnel, J. (2016). Coming back to work in the morning: Psychological detachment and reattachment as predictors of work engagement. Journal of Occupational Health Psychology, 21, 379-390.

https://doi.org/10.1037/ocp0000020

Spector, P.E., \& Jex, S.M. (1998). Development of Four Self-Report Measures of Job Stressors and Strain: Interpersonal Conflict at Work, Organizational Constraints Scale, Quantitative Workload Inventory, and Physical Symptoms Inventory. Journal of Occupational Health Psychology, 3, 356 - 367. http://dx.doi.org/10.1037/ocp0000031

Steger, M.F., \& Dik, B.J. (2010). Work as meaning: Individual and organizational benefits of engaging in meaningful work. In P. A. Linley, S. Harrington, \& N. Garcea (Eds.), Oxford library of psychology. Oxford handbook of positive psychology and work (p. 131-142). Oxford University Press.

Tadić, M., Bakker, A. B., \& Oerlemans, W. G. (2015). Challenge versus hindrance job demands and well-being: A diary study on the moderating role of job resources. Journal of Occupational and Organizational Psychology, 88, 702-725. https://doi.org/10.1111/joop.12094

Trougakos, J. P., \& Hideg, I. (2009). Momentary work recovery: The role of within-day work breaks. In Current perspectives on job-stress recovery (pp. 37-84). Emerald Group Publishing Limited. 
Weigert, B., \& Agrawal, S. (2018). Employee burnout, part 1: The 5 main causes. Retrieved from https://www.gallup.com/workplace/237059/employee-burnoutpart-main-causes.aspx

Weinstein, N., \& Ryan, R. M. (2010). When helping helps: Autonomous motivation for prosocial behavior and its influence on well-being for the helper and recipient. Journal of Personality and Social Psychology, 98, 222244. https://doi.org/10.1037/a0016984

Zacher, H., Brailsford, H. A., \& Parker, S. L. (2014). Micro-breaks matter: A diary study on the effects of energy management strategies on occupational wellbeing. Journal of Vocational Behavior, 85, 287-297.

https://doi.org/10.1016/j.jvb.2014.08.005 


\section{Appendix A: Baseline Survey Items}

\section{Hours worked per week}

On average, how many hours do you work per week?

Fill-in: hours

\section{Department}

What department do you work in? (Select one):

Sales

Marketing

Customer Care

Partner Management

Warehouse

Accounting

MIS

Administrative

Executive

HR

Managed Staffing

Personal Systems Group

Project Management

Staffing

PreSales

Delivery

End of Services

Managed Services

\section{Tenure in...}

Organization: How many years have you been working in your current organization?

Fill-in: years

\section{Job Level}

Which best describes your job level (Select one):

Front Line Worker

Lead

Supervisor

Manager

Director

VP

Executive 
Age

What is your age?

Fill-in: years

\section{Ethnicity}

What is your ethnicity?

Response Options (Circle all that apply): (a) White (non-Hispanic), (b) Hispanic/Latino, (c) African American, (d) Asian, (e) Native American, (f) Native Alaskan or Pacific Islander, or (g) Other (please specify:

\section{Gender}

What is your gender?

Response Options (Circle one): (a) Man or (b) Non-Binary/Third Gender or (c) Prefer not to disclose or (d) Woman or (e) A gender other than those listed

\section{Education Level}

What is the highest level of education you have completed?

Response Options (Circle one): (a) High school/GED, (b) Some college, (c) 2-year college degree (Associate's), (d) 4-year college degree (Bachelor's), (e) Advanced degree (Master's or other), or (f) Other (please specify: 


\section{Appendix B: Day-Level Noon Survey Items}

Challenge and Hindrance Stressors (Rodell \& Judge, 2009)

To what extent do you agree with the following statements this morning?

This morning at work....

\section{Challenge Stressors}

1. I had to work on a large number of projects and/or assignments.

2. My job required me to work very hard.

3. The volume of work that had to be accomplished in the allocated time was difficult.

4. I experienced severe time pressures in my work.

5. I felt the amount of responsibility I have at work.

6. I was responsible for counseling others and/or helping them solve their problems.

7. My job required a lot of skill.

8. My job required me to use a number of complex or high-level skills.

\section{Hindrance Stressors}

1. I had to go through a lot of red tape to get my job done.

2. My duties and work objectives were unclear to me.

3. I did not fully understand what was expected of me.

4. I felt there was clear, planned goals and objectives for my work. (R)

5. I received conflicting requests from two or more people.

6. I worked with two or more groups who operate quite differently.

7. I received assignments without adequate resources and materials to execute them.

8. I had many hassles to go through to get projects/assignments done.

Response options: (1) Strongly Disagree - (5) Strongly Agree

\section{Energy Management Strategies (Parker et al, 2017)}

Please indicate the extent to which you used the following strategies this morning at work.

This morning at work, I managed my energy by...

Organizing Strategies

1. Checking and updating my schedule

2. Making a to-do list

3. Setting a new goal

Meaning-Related Strategies

1. Reflecting on the meaning of my work

2. Reflecting on how I make a difference at work

3. Focusing on what gives me joy at work

\section{Prosocial Strategies}

4. Making time to show gratitude to someone I work with

5. Doing something that will make a colleague happy

6. Offering help to someone at work 
Response options: (1) not at all, (2) a little bit, (3) A Moderate Amount, (4) quite a bit, (5) very much 


\section{Appendix C: Day-Level Post-Work Survey Items}

Goal Success Scale (Low et al., 2017; adapted for day-level)

Reflecting upon work this afternoon, please indicate to what extent you agree with the following statements.

This afternoon at work....

1. I made great progress towards my goals.

2. My attempts to achieve my goals have been successful.

3. I was satisfied with the progress I have made towards my goals.

Response options: (1) strongly disagree - (5) strongly agree

State Work Engagement (UWES; Schaufeli et al., 2006; Validated by Breevaart et al, 2012)

Reflecting upon this afternoon, please indicate to what extent you agree with the following statements.

This afternoon at work...

Vigor

1. I felt bursting with energy.

2. I felt strong and vigorous at my job.

3. When I got up this morning, I felt like going to work.

Dedication

1. I was enthusiastic about my job.

2. My job inspired me.

3. I was proud of the work that I did.

Absorption

1. I felt happy when I was working intensely.

2. I was immersed in my work.

3. I got carried away when I was working.

Response options: (1) strongly disagree - (5) strongly agree

Relational Energy Scale (Owens, Baker, Sumpter, \& Cameron, 2016)

Reflecting upon work this afternoon, please indicate to what extent you agree with the following statements.

This afternoon at work...

1. I felt invigorated when I interacted with people.

2. After interacting with people, I felt more energy to do my work.

3. I felt increased vitality when working with others.

4. I went to people when I needed to be "pepped up".

5. After exchanges with others, I felt more stamina to do my work. Response options: (1) strongly disagree - (5) strongly agree 